\title{
Genomic Analysis of Clavibacter michiganensis Reveals Insight Into Virulence Strategies and Genetic Diversity of a Gram-Positive Bacterial Pathogen
}

\author{
Shree P. Thapa, ${ }^{1}$ Sivakumar Pattathil, ${ }^{2}$ Michael G. Hahn, ${ }^{2}$ Marie-Agnès Jacques, ${ }^{3}$ Robert L. Gilbertson, ${ }^{1}$ \\ and Gitta Coaker ${ }^{1,+}$ \\ ${ }^{1}$ Department of Plant Pathology, University of California, Davis, California, U.S.A.; ${ }^{2}$ Complex Carbohydrate Research Center, \\ The University of Georgia, Athens, Georgia, U.S.A.; and ${ }^{3}$ IRHS, Agrocampus-Ouest, INRA, Université d'Angers, Beaucouzé, \\ France
}

Accepted 2 February 2017.

\begin{abstract}
Clavibacter michiganensis subsp. michiganensis is a grampositive bacterial pathogen that proliferates in the xylem vessels of tomato, causing bacterial canker disease. In this study, we sequenced and assembled genomes of $11 C$. michiganensis subsp. michiganensis strains isolated from infected tomato fields in California as well as five Clavibacter strains that colonize tomato endophytically but are not pathogenic in this host. The analysis of the $\boldsymbol{C}$. michiganensis subsp. michiganensis genomes supported the monophyletic nature of this pathogen but revealed genetic diversity among strains, consistent with multiple introduction events. Two tomato endophytes that clustered phylogenetically with $C$. michiganensis strains capable of infecting wheat and pepper and were also able to cause disease in these plants. Plasmid profiles of the California strains were variable and supported the essential role of the pCM1-like plasmid and the CelA cellulase in virulence, whereas the absence of the pCM2-like plasmid in some pathogenic $C$. michiganensis subsp. michiganensis strains revealed it is not essential. A large number of secreted $C$. michiganensis subsp. michiganensis proteins were carbohydrate-active enzymes (CAZymes). Glycome profiling revealed that $C$. michiganensis subsp. michiganensis but not endophytic Clavibacter strains is able to extensively alter tomato cell-wall composition. Two secreted CAZymes found in all $C$. michiganensis subsp. michiganensis strains, CelA and PelA1, enhanced pathogenicity on tomato. Collectively, these results provide a deeper understanding of C. michiganensis subsp. michiganensis diversity and virulence strategies.
\end{abstract}

Plants can be infected by both gram-negative and grampositive bacteria. Gram-positive bacterial pathogens can cause plant diseases that are responsible for substantial crop losses, including species of the genera Clavibacter, Streptomyces, and Rhodococcus (Francis et al. 2010). The genus Clavibacter contains one species, Clavibacter michiganensis, which proliferates in the xylem and is able to infect a wide range of plants (Eichenlaub et al. 2006). Subspecies of C. michiganensis differentially infect various dicot and monocot hosts, including: tomato, potato, pepper, bean, wheat, maize, and alfalfa (Eichenlaub

${ }^{\dagger}$ Corresponding author: G. Coaker; E-mail: glcoaker@ucdavis.edu

*The $\boldsymbol{e}$-Xtra logo stands for "electronic extra" and indicates that five supplementary figures and eight supplementary tables are published online.

(c) 2017 The American Phytopathological Society and Gartemann 2011; González and Trapiello 2014). Despite the importance of these pathogens, there are no commercial cultivars with high levels of resistance or effective chemical control strategies. Plant-pathogenic Clavibacter strains initially establish latent infections, which facilitate pathogen colonization of plants as well as seed contamination (Gitaitis et al. 1991). Furthermore, endophytic Clavibacter strains, which are capable of colonizing vascular tissue without causing disease symptoms, have been frequently described (Ding et al. 2011; Eichenlaub and Gartemann 2011).

C. michiganensis subsp. michiganensis causes bacterial canker, which is one of the most important bacterial diseases of tomato (de León et al. 2011; Mansfield et al. 2012). Bacterial canker can cause substantial losses in greenhouse and field production systems, including losses in processing tomato production in California. C. michiganensis subsp. michiganensis gains entry into the plant through contaminated seeds, wounds, broken trichomes, or hydathodes and then proliferates in xylem vessels (Eichenlaub et al. 2006; Sen et al. 2015). Systemic infection results in unilateral leaf wilting, formation of stem canker and, in severe cases, wilting, necrosis, and death of the entire plant (de León et al. 2011). Inside stems, vascular discoloration and degradation of pith tissues is typically observed. The economic threat and the challenges to manage this disease have led to the inclusion of this pathogen as a quarantine agent in Europe, Asia, Africa, and the Caribbean (Eichenlaub and Gartemann 2011; Official Journal of the European Communities 2000). On tomato, nonpathogenic Clavibacter strains are frequently seed-associated and can be phylogenetically distinct from pathogenic $C$. michiganensis subsp. michiganensis strains based on multilocus sequencing (Jacques et al. 2012; Yasuhara-Bell and Alvarez 2015; Zaluga et al. 2013).

Several gram-negative bacterial plant pathogens, such as Pseudomonas syringae, Ralstonia solanacearum, and Xanthomonas euvesicatoria, have been extensively studied, and scientists possess a detailed understanding of the molecular mechanisms regulating virulence (Cunnac et al. 2011; Dou and Zhou 2012; Toruño et al. 2016). A major virulence component of most gramnegative bacterial pathogens is the type III secretion system (T3SS), which enables the delivery of effector proteins into host cells to facilitate colonization and disease (Cornelis 2010; Cunnac et al. 2011). In contrast, gram-positive bacteria lack the T3SS and a mechanistic understanding of how they cause disease and suppress host defenses is largely unknown. Analyses of $C$. michiganensis subsp. michiganensis strains collected from diverse geographic origins have revealed diversity with respect to plasmid composition, plasmid number, and the presence of putative chromosomally 
encoded pathogenicity genes (Jacques et al. 2012; MilijaševićMarčić et al. 2012; Quesada-Ocampo et al. 2012; Tancos et al. 2015).

Investigations of the molecular basis of pathogenicity have been primarily performed on $C$. michiganensis subsp. michiganensis NCPPB382 (Eichenlaub and Gartemann 2011; Sen et al. 2015). The NCPPB382 genome has been sequenced and contains two plasmids, pCM1 and pCM2 (Gartemann et al. 2008; Meletzus et al. 1993). The virulence factors celA and pat-1 are encoded on pCM1 and $\mathrm{pCM} 2$, respectively. Loss of either plasmid decreases virulence, whereas a plasmid-free derivative was unable to induce disease symptoms but was still able to colonize tomato (Gartemann et al. 2003; Meletzus et al. 1993). NCPPB382 possesses the chp/tomA pathogenicity island, which contains multiple glycosidases and proteases as well as a tomatinase involved in detoxification of the tomato alkaloid $\alpha$-tomatine (Gartemann et al. 2008; Kaup et al. 2005). Deletion of the entire chp/tomA region rendered NCPPB382 unable to induce disease symptoms (Chalupowicz et al. 2012). Recently, several genes have been identified that are important for localized infections, including serine proteases and two cell walldegrading enzymes (PCWDEs) (Chalupowicz et al. 2017).

In the present study, we sequenced and assembled high-quality genomes of 11 pathogenic C. michiganensis subsp. michiganensis strains isolated from tomato plants in California. In addition, we sequenced the genomes of five Clavibacter strains that were isolated from surface-disinfested tomato parts and colonized tomato endophytically but were not pathogenic on this host. We refer to these strains as tomato endophytes, as this term most commonly refers to microorganisms that can be isolated from surfacedisinfested plant tissues in the absence of visible disease symptoms (Hardoim et al. 2015). We performed a comparative genomics analysis with the complete sequences of these strains, coupled with functional analyses of conserved genomic regions. Taken together, this study provides novel insights into genetic diversity and virulence strategies of diverse $C$. michiganensis subsp. michiganensis strains.

\section{RESULTS}

\section{Phenotypic analyses, phylogeny, and genome sequencing} of Clavibacter strains.

Over $95 \%$ of the United States processing tomatoes are grown in California (Geisseler and Horwath 2014). In California, C. michiganensis subsp. michiganensis infection is a reoccurring problem in greenhouse production of transplants and in the field. In order to investigate pathogenicity and aggressiveness of different strains, the tomato cultivar Early Pak 7 was inoculated by stem prick with 12 Clavibacter strains isolated from tomato plants in California over different years and locations as well as the reference $C$. michiganensis subsp. michiganensis strain NCPPB382 (Table 1). Bacterial titers, leaf wilting, and canker formation were analyzed. Bacterial titers were analyzed from infected stem material 14 days postinoculation (dpi). With the exception of strain CASJ009, all strains grew to high titers and were pathogenic in tomato, although there was up to an eightfold difference in bacterial growth among pathogenic strains (Fig. 1A to D). These results indicated that these 11 California strains are $C$. michiganensis subsp. michiganensis. In contrast, the Clavibacter strain CASJ009 did not cause disease symptoms (Fig. $1 \mathrm{~A}$ to D). However, by $14 \mathrm{dpi}$, CASJ009 was recovered from vascular tissues above and below the site of inoculation (Supplementary Fig. S1C) and as far as $9 \mathrm{~cm}$ above the inoculation site. Taken together, these results indicate that CASJ009 is not a strain of C. michiganensis subsp. michiganensis but is an endophyte in tomato.

In order to investigate the genetic relationship of the C. michiganensis subsp. michiganensis strains from California with previously characterized $C$. michiganensis subsp. michiganensis strains, other Clavibacter subspecies, and nonpathogenic Clavibacter strains, we used a multilocus sequence analysis (MLSA) approach. We first verified that strains described as nonpathogenic on tomato do not cause disease symptoms on tomato and can act as endophytes. These analyses included many strains whose genomes have not been sequenced, but MLSA data are available (Jacques et al. 2012). Pathogenic strains of $C$. michiganensis subspecies included in the analysis were $C$. michiganensis subsp. tessellarius (NZ_LQXA00000000, wheat), C. michiganensis subsp. insidiosus (NZ_CP011043, alfalfa), C. michiganensis subsp. nebraskensis (NC_020891, corn), C. michiganensis subsp. capsici (NZ_CP012573, pepper), and C. michiganensis subsp. sepedonicus (NC_010407, potato) (Bentley et al. 2008; Lu et al. 2015b). Concatenated sequences from six housekeeping genes (atpD, $d n a K, g y r B, p p K$, recA, and $r p o B$ ) were used to generate a maximum likelihood phylogeny. The 11 pathogenic strains from California were placed in a large monophyletic clade with other C. michiganensis subsp. michiganensis strains, confirming that these are strains of $C$. michiganensis subsp. michiganensis (Fig. 1E). However, this analysis revealed that the California C. michiganensis subsp. michiganensis strains are not clonal, as they were placed in different subclades within the $C$. michiganensis subsp. michiganensis clade. This level of genetic diversity suggests multiple introduction events in California.

Table 1. Clavibacter strains sequenced in this study ${ }^{\mathrm{a}}$

\begin{tabular}{|c|c|c|c|c|c|c|c|c|}
\hline Strains & Year isolated & Path $^{\text {b }}$ & Seq platform & Contigs & N50 value & Size (bp) & Accession no. & Plasmids \\
\hline CASJ001 & 1999 & + & MiSeq, PacBio & 4 & $1,764,894$ & $3,423,339$ & MDHB00000000 & pCM1 \\
\hline CASJ002 & 1999 & + & MiSeq, PacBio & 3 & $3,284,808$ & $3,423,641$ & MDHC00000000 & $\mathrm{pCM} 1 / \mathrm{pCM} 2$ \\
\hline CASJ003 & 1999 & + & MiSeq & 315 & 17,464 & $3,294,503$ & MDHD00000000 & $\mathrm{pCM} 1 / \mathrm{pCM} 2$ \\
\hline CASJ004 & 1999 & + & MiSeq & 477 & 14,451 & $3,351,833$ & MDHE00000000 & $\mathrm{pCM} 1 / \mathrm{pCM} 2$ \\
\hline CASJ005 & 2001 & + & MiSeq & 321 & 16,819 & $3,284,480$ & MDHF00000000 & $\mathrm{pCM} 1 / \mathrm{pCM} 2$ \\
\hline CASJ006 & 2002 & + & MiSeq, PacBio & 4 & $3,215,422$ & $3,499,162$ & MDHG00000000 & $\mathrm{pCM} 1 / \mathrm{pCM} 2$ \\
\hline CASJ007 & 2011 & + & MiSeq, PacBio & 11 & 480,089 & $3,400,049$ & MDHH00000000 & pCM1 \\
\hline CASJ008 & 2002 & + & HiSeq & 39 & $2,059,966$ & $3,392,817$ & MDHI00000000 & $\mathrm{pCM} 1 / \mathrm{pCM} 2$ \\
\hline CAYO001 & 2001 & + & MiSeq, PacBio & 3 & $3,331,437$ & $3,481,307$ & MDHL00000000 & $\mathrm{pCM} 1 / \mathrm{pCM} 2$ \\
\hline CA00001 & 2000 & + & HiSeq & 120 & 90,378 & $3,625,805$ & MDHK00000000 & $\mathrm{pCM} 1 / \mathrm{pCM} 2$ \\
\hline CA00002 & 2000 & + & HiSeq, PacBio & 4 & $3,281,486$ & $3,371,744$ & MDHM00000000 & $\mathrm{pCM} 1 / \mathrm{pCM} 2$ \\
\hline CASJ009 & 2011 & - & MiSeq, PacBio & 2 & $3,279,109$ & $3,422,081$ & MDHJ00000000 & pSap1 \\
\hline CFBP7494 & 1999 & - & HiSeq & 15 & 439,451 & $3,425,817$ & MDJW00000000 & - \\
\hline CFBP7576 & 1997 & - & HiSeq & 372 & 20,825 & $3,399,000$ & MDJX00000000 & $\mathrm{pCM} 1 / \mathrm{pCM} 2$ \\
\hline CFBP8017 & 2006 & - & HiSeq & 65 & 95,162 & $3,284,576$ & MDJY00000000 & - \\
\hline CFBP8019 & - & - & HiSeq & 18 & 339,261 & $3,076,288$ & MDJZ00000000 & - \\
\hline
\end{tabular}

\footnotetext{
${ }^{\text {a }}$ Pathogenicity was verified on tomato and all pathogenic strains are Clavibacter michiganensis subsp. michiganensis.

${ }^{\mathrm{b}}$ Path = pathogenicity on tomato.
} 

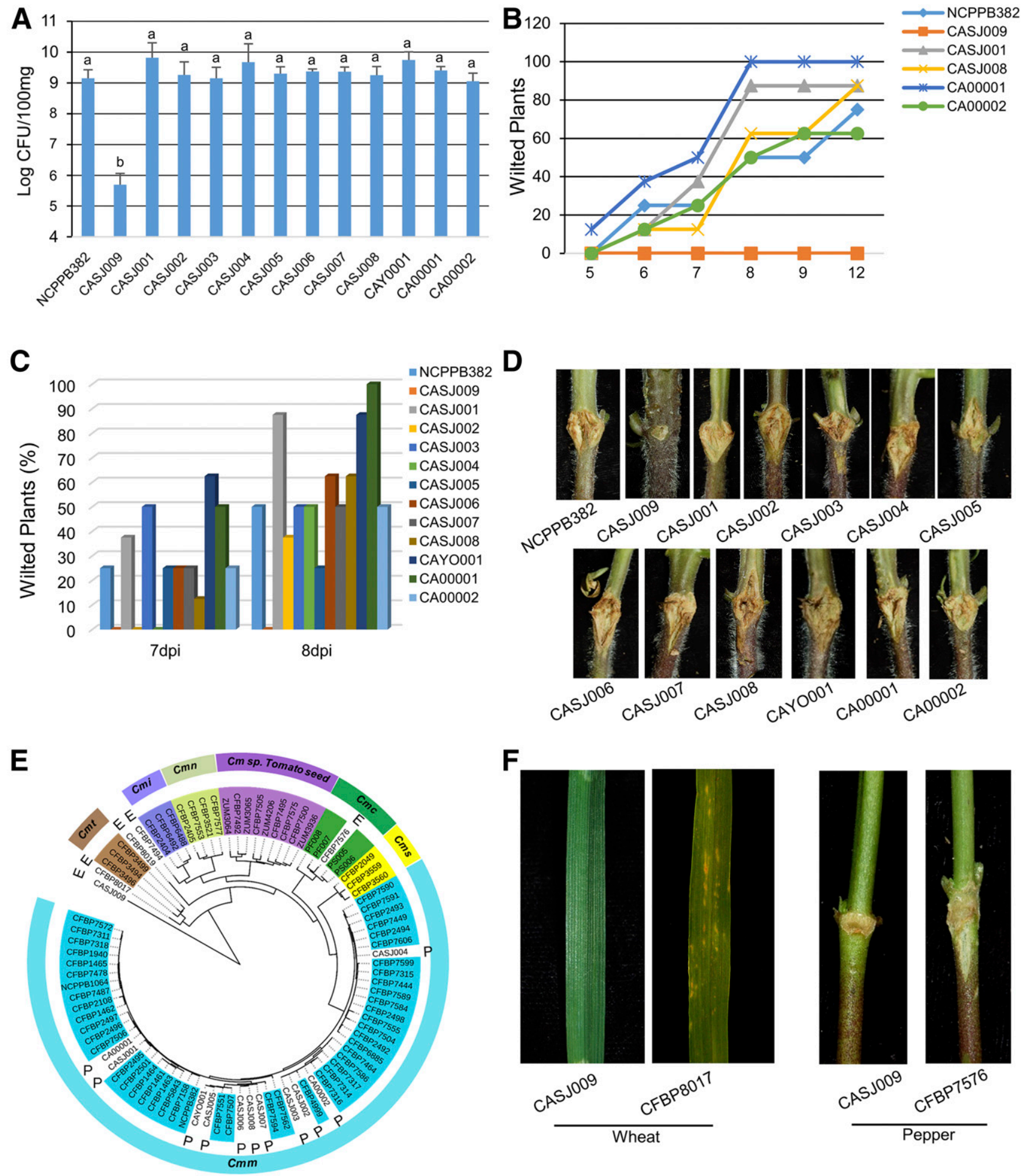

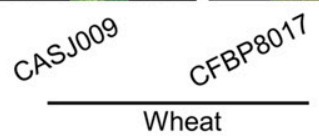

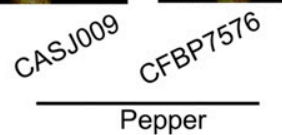

Fig. 1. Pathogenicity and phylogenetic analyses of Clavibacter strains. Three-week-old tomato plants (Solanum lycopersicum cv. Early Pak 7) were inoculated with wild-type Clavibacter michiganensis subsp. michiganensis CASJ001, CASJ002, CASJ003, CASJ004, CASJ005, CASJ006, CASJ007, CASJ008, CAYO001, CA00001, CA0002, NCPPB382, and the endophyte CASJ009. Tomato stems were stabbed with a needle and inoculated with $5 \mu 1$ of $C$. michiganensis subsp. michiganensis at $10^{7} \mathrm{CFU} / \mathrm{ml}$. A, Bacterial titers in infected tomato stem tissue 14 days postinoculation (dpi). Stem sections were taken 1 $\mathrm{cm}$ above the inoculation point to determine bacterial titers. No significant differences were detected by Tukey's honest significant difference, $P<0.05, n=18$. $\mathbf{B}$, Time course of the appearance of wilting of the first leaflet above the inoculation point was monitored over 12 days. Plants were inoculated as described above, $n=18$. The $x$ axis indicates days postinoculation. C, Graph of wilting severity across all strains at $7 \mathrm{dpi}, n=18$. D, Representative tomato stems exhibiting canker symptoms after inoculation with different $C$. michiganensis subsp. michiganensis strains. Images were taken 14 dpi. CASJ009 is an endophyte. E, Phylogeny of strains of $C$. michiganensis subspecies based on concatenated sequences of six housekeeping genes (atpD, dnaK, gyrB, ppK, recA, and rpoB). A maximum likelihood approach was used to obtain the phylogenetic tree, using MEGA software version 6 with 1,000 bootstrap replicates. E = endophyte/nonpathogen, $\mathrm{P}=$ pathogen, no color $=$ strains sequenced in the present study, Cmt $=$ Clavibacter michiganensis subsp. tessellarius, Cmi $=$ Clavibacter michiganensis subsp. insidiosus, Cmn = Clavibacter michiganensis subsp. nebraskensis, $\mathrm{Cm}$ sp. tomato seed $=$ Clavibacter isolated from tomato seeds, $C m c=$ Clavibacter isolated from pepper, and Cms = Clavibacter michiganensis subsp. sepedonicus. Unless otherwise noted, all pathogenic strains are Clavibacter michiganensis subsp. michiganensis. F, Representative wheat leaves exhibiting symptoms after inoculation with CFBP8017 and representative pepper stems exhibiting canker symptoms after inoculation with CFBP7576 strains. Stem and leaves images were taken 14 dpi. CASJ009 is a nonpathogenic strain. 
Endophytic Clavibacter strains were distributed in different clades and three clustered with other $C$. michiganensis subspecies, which are known pathogens of wheat, pepper, and alfalfa (Fig. $1 \mathrm{E})$. In order to determine if these endophytic strains could infect and cause disease in the crops infected by the $C$. michiganensis subspecies that they clustered with, inoculations were performed on wheat and pepper. Clavibacter isolate CFBP8017 clustered with $C$. michiganensis subsp. tesssellarius strains that infect wheat and it induced mosaic disease symptoms on wheat plants (Fig. 1F). Clavibacter isolate CFBP7576 clusters with C. michiganensis subsp. capsici strains that infect pepper and it induced stem canker symptoms on pepper plants (Fig. 1F). In contrast, the Clavibacter isolate CASJ009, which does not cluster with any known pathogens, is unable to cause disease symptoms on either wheat or pepper.

In order to further investigate the genetic diversity of the Clavibacter strains able to colonize tomato, we sequenced and assembled 16 genomes using sequencing by synthesis on the Illumina HiSeq 2500 or Miseq platforms. We included the 11 C. michiganensis subsp. michiganensis strains collected in California as well as the five tomato endophytes collected from tomato plant materials, i.e., CASJ009 isolated from a tomato stem in California and four strains from the CFBP (French Collection of Plant-Associated Bacteria) (Table 1). CFBP7494 was isolated from seeds produced in Chile, whereas CFBP8017 and CFBP8019 were isolated from seeds in The Netherlands. We were unable to obtain information about the origin of CFBP7576. SMRT (single molecule, real-time) sequencing on the PacBio platform was also employed for seven strains in order to facilitate more complete genome assemblies. To generate draft genomes for each strain, the assemblies with the highest N50 value and assembly size were selected and were merged by Mix pipeline (Soueidan et al. 2013). The genome sizes of the Clavibacter strains ranged from 3.27 to $3.48 \mathrm{Mb}$, with an average mean coverage of $100 \times$. Assemblies using Illumina and PacBio sequence data enabled the generation of complete or near-complete genome assemblies. General properties of all the genomes are summarized in Table 1.

To facilitate a high resolution comparison of the sequenced Clavibacter species, core orthologous proteins were identified. The core genome common to all 16 strains sequenced in this study as well as C. michiganensis subsp. michiganensis NCPPB382, C. michiganensis subsp. sepedonicus ATCC33113, C. michiganensis subsp. nebraskensis NCPPB2581, C. michiganensis subsp. insidiosus R1-1, C. michiganensis subsp. tessellarius DOAB609, and C. michiganensis subsp. capsici PF008 was determined. A total of 1,358 orthologous proteins were identified. The orthologous proteins were concatenated for each strain (476,583 amino acid residues) and a maximum likelihood approach was employed to generate a phylogenetic tree. Similar to the results obtained with the MLST analysis, the California $C$. michiganensis subsp. michiganensis strains and the reference strain were placed into a monophyletic clade (Fig. 2A). The phylogenetic analyses with the core orthologous sequences further refined the genetic relationship among the California C. michiganensis subsp. michiganensis strains by revealing five subclades. Several strains clustered together in these subclades, including strains CASJ002, CA00002, and CASJ003, were isolated in 1999 and 2000; CASJ005 and CAYO001 were isolated in 2001; and CASJ006 and CASJ008 were isolated in 2002. These results suggest an association between the subclade and the years in which the strains were isolated. The California strains CASJ001 and CASJ007 were most closely related to the reference strain NCPPB382. Collectively, these data demonstrate that California $C$. michiganensis subsp. michiganensis strains are not clonal and support the concept of multiple introductions with seed. Also consistent with the results of the MLST analysis, the endophytic strains isolated from tomato were not monophyletic and were more diverse compared with
C. michiganensis subsp. michiganensis strains (Fig. 2A). These results clearly show that genetically diverse Clavibacter strains can colonize tomato endophytically.

\section{Comparative analyses.}

We next compared the genomes of a pathogenic California C. michiganensis subsp. michiganensis strain (CASJ002), the California tomato endophyte (CASJ009), and the C. michiganensis subsp. michiganensis reference strain NCPPB382. The three genomes were each predicted to encode an average of 3,200 proteincoding sequences. Using a value of $>90 \%$ amino acid identity to indicate common genes, the two $C$. michiganensis subsp. michiganensis strains (CASJ002 and NCPPB382) shared 93\% $(2,955)$ of their predicted genes. In contrast, the endophyte (CASJ009) shared only around $70 \%(2,264)$ of its predicted genes with the pathogenic C. michiganensis subsp. michiganensis strains. Bacterial chromosomes were visualized using Circos plots. There was a higher level of conservation in gene content and organization between the two C. michiganensis subsp. michiganensis strains (CASJ002 and NCPPB382) compared with the endophyte CASJ009 (Fig. 2B and C).The genome sequences of $C$. michiganensis subsp. michiganensis strains CASJ002 and NCPPB382 also display a higher levels of colinearity and genome-wide sequence similarity, compared with the tomato endophyte CASJ009 (Fig. 2B and C).

Genomic islands (GIs) are clusters of genes acquired via horizontal transfer. GIs have been demonstrated to significantly impact bacterial adaptation, evolution and pathogenicity (Bellanger et al. 2014). To identify GIs, IslandViewer, which integrates multiple GI prediction methods (Dhillon et al. 2015), was used. The largest GI present in all pathogenic $C$. michiganensis subsp. michiganensis strains was the approximately 129-kb chp/tomA region (Fig. 2B and C; Supplementary Fig. S2). Chp/tomA is required for NCPPB382 pathogenicity on tomato, as a mutant having a deletion of the entire chp/tomA GI exhibited reduced growth in tomato and was unable to cause disease (Gartemann and Eichenlaub 2001; Gartemann et al. 2008). Consistent with the inability of CASJ009, CFBP7494, CFBP7576, CFBP8017, and CFBP8019 to cause disease symptoms in tomato, the chp/tomA GI is lacking in these strains, whereas it was present in C. michiganensis subsp. michiganensis strains. Indeed, Chp/tomA is the only GI universally found in $C$. michiganensis subsp. michiganensis strains. Most of the other GIs present in sequenced C. michiganensis subsp. michiganensis strains are variable, and hallmarks of GI loss were also detected. The GIs present in the California $C$. michiganensis subsp. michiganensis strains and their locations are provided in Supplementary Table S3.

\section{Plasmid presence uncouples pathogenicity and growth in tomato.}

Bacterial plasmids play an important role in acquisition of new traits and can impact virulence. We investigated the presence and composition of plasmids in the 16 Clavibacter strains sequenced in this study. The presence of plasmids with similarity to pCM1 and $\mathrm{pCM} 2$ were detected based on similarity in the plasmid backbone (replication and partitioning genes) and conjugal transfer genes as well as the presence of celA (pCM1) or pat-1 (pCM2). We detected a range in plasmid sizes for both pCM1and pCM2-like plasmids, 31 to $59 \mathrm{~kb}$ and 64 to $109 \mathrm{~kb}$, respectively. All pathogenic C. michiganensis subsp. michiganensis strains possessed a plasmid with similarity to pCM1 (Supplementary Fig. S3). For example, the plasmid present in strain CASJ001 was most closely related to NCPPB382's pCM1, consistent with their close relationship in the phylogenic analyses. However, the pCM1-like plasmids in the other California C. michiganensis subsp. michiganensis strains differed substantially from that in NCPPB382 in terms of their overall size and gene content. 
Importantly, C. michiganensis subsp. michiganensis strains CASJ001 and CASJ007 lacked the pCM2-like plasmid but were still pathogenic in tomato to a similar extent as strains possessing pCM2 (Table 1; Figs. 1 and 3A). The absence of the pCM2-like plasmid in these strains clearly indicates that the presence $\mathrm{pCM} 2$, which is required for symptom development in NCPPB382 (Dreier et al. 1997), is not universally required for pathogenicity (Fig. 3A). A pCM2-like plasmid was present in other sequenced C. michiganensis subsp. michiganensis strains, but its overall size and gene content differed substantially among strains. pCM1- and pCM2-like plasmids were also present in the endophyte CFBP7576, consistent with it being pathogenic on pepper, whereas none of the other endophytic Clavibacter strains possessed plasmids with similarity to pCM1 or pCM2 (Table 1). The endophyte CASJ009 possesses a novel plasmid, pCMsap1, which lacks sequence similarity with pCM1 and pCM2 (Table 1). These data reveal considerable diversity in the presence and composition of plasmids in C. michiganensis subsp. michiganensis and, further, highlight the importance of investigating virulence mechanisms in diverse $C$. michiganensis subsp. michiganensis strains.

In order to investigate the relative importance of pCM1 and pCM2-like plasmids, we sought to remove (cure) them and then to assess disease development and pathogen multiplication in
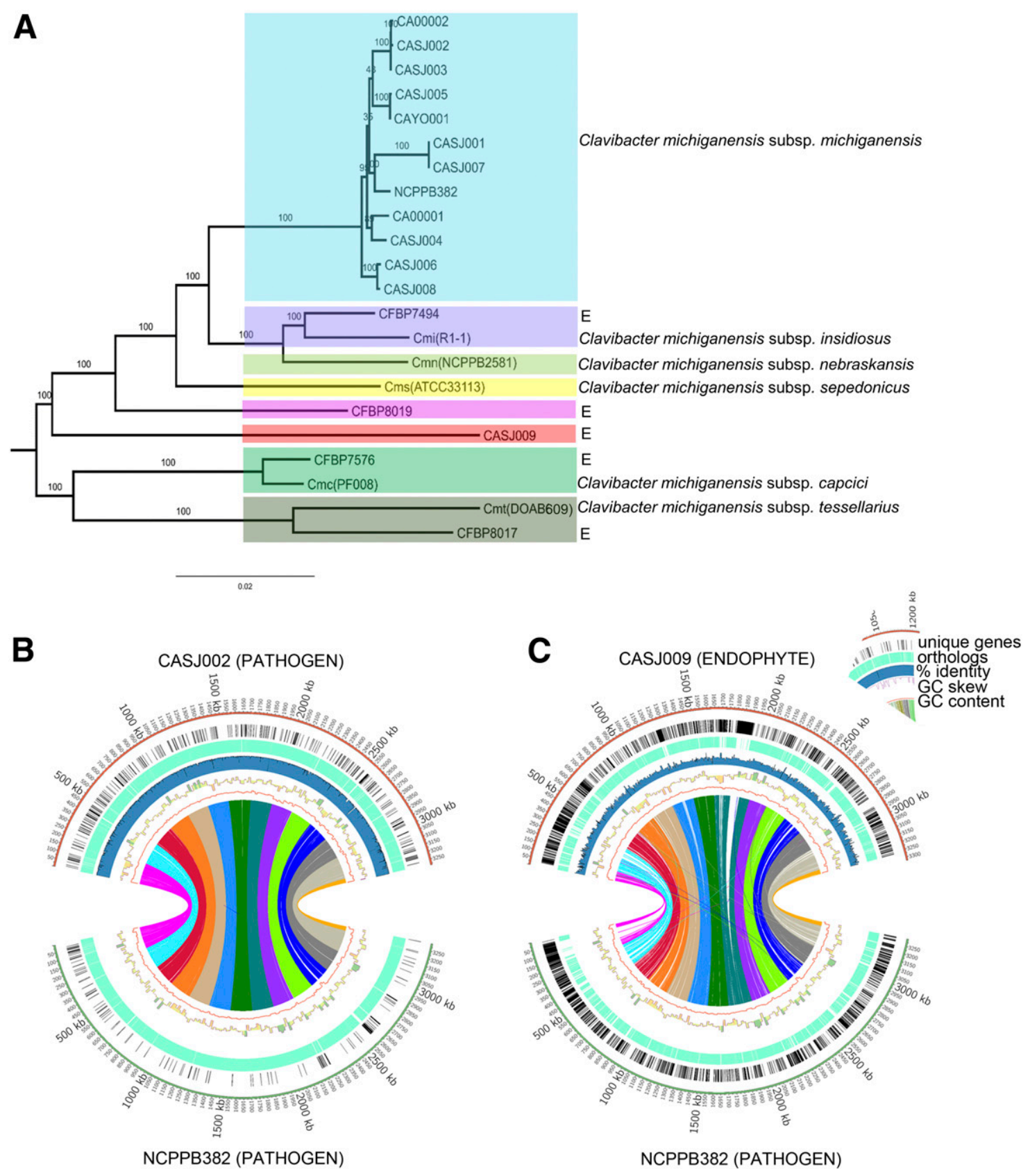

Fig. 2. Genome-wide comparison of Clavibacter strains. A, Phylogeny of Clavibacter michiganensis subsp. michiganensis and other Clavibacter species based on orthologous genes. In total, 1,358 orthologous proteins were concatenated in an alignment of 476,583 amino acids. A maximum likelihood approach was used to generate the phylogeny with 1,000 bootstrap replicates. Bootstrap values are indicated at each node. $\mathrm{E}=$ endophyte. $\mathbf{B}$ and $\mathbf{C}$, Circos plots depicting genome-wide comparisons of pathogen CASJ002, the NCPP382 reference strain, and the CASJ009 endophyte. The Circos plot illustrates regions of significant similarity between CASJ002 to NCPPB382. Chromosomes are depicted in arbitrary shades (outer ring). The two pathogens are more closely related to each other than to the endophytic strain. The endophyte Clavibacter sp. strain CASJ009 is lacking many genes associated with virulence and has a larger number of unique genes. 
A

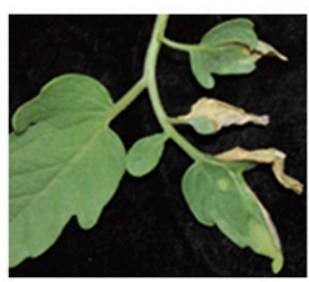

Pathogenicity: Pathogen Strain: CASJ001

Plasmids: $\mathrm{pCM} 1$

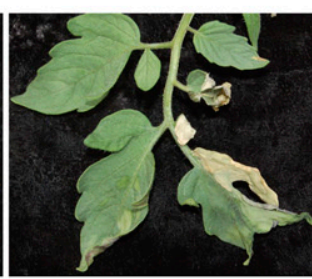

Pathogen

CASJ002

pCM1 \& pCM2

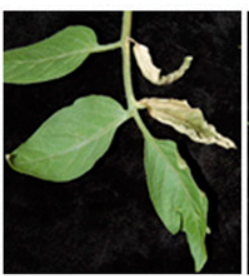

Pathogen

NCPPB382

pCM1 \& pCM2

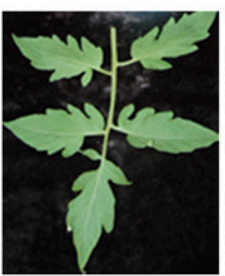

Endophyte

CASJ009

pCMsap1

\section{B}

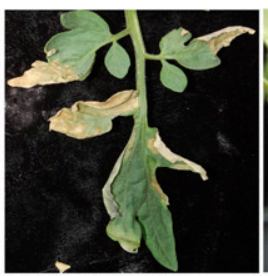

Pathogenicity: Pathogen Strain: CASJ001 Plasmids: $\mathrm{pCM} 1$

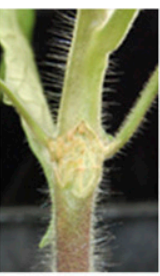

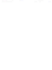

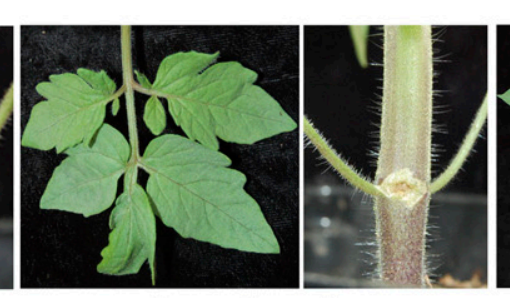

Non-pathogenic CASJ001 $1 \mathrm{p} 1$ None

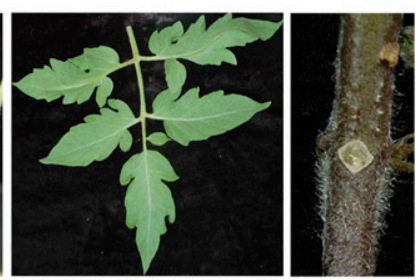

Mock

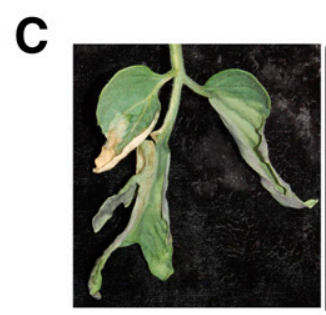

Pathogenicity: Pathogen Strain: CASJ002 Plasmids: $\mathrm{pCM} 1$ \& $\mathrm{pCM} 2$
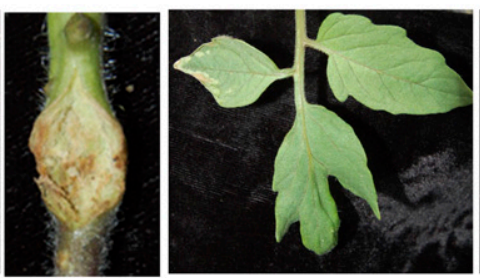

Weakly pathogenic CASJ002 $\Delta$ p2 pCM1
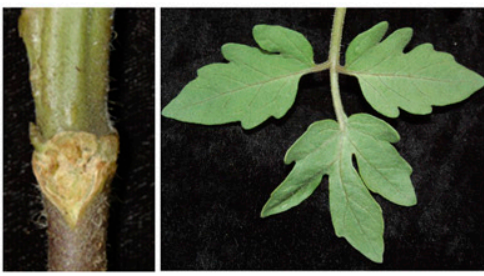

Non-pathogenic CASJ002 $\Delta \mathrm{p} 1 \Delta 2$ None
D

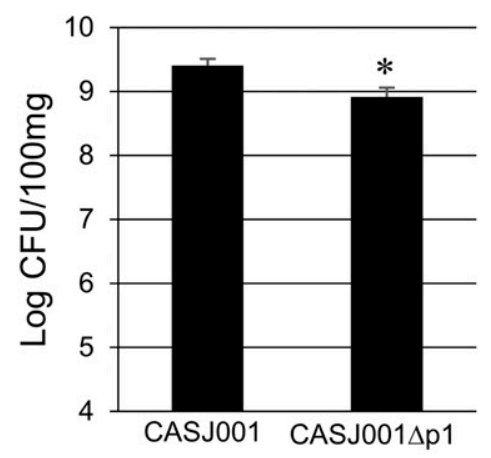

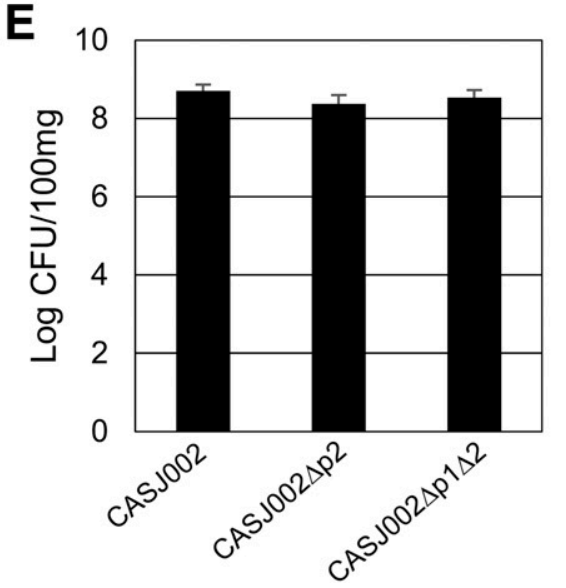

Fig. 3. Plasmid presence can uncouple bacterial virulence and growth in tomato. A, Representative bacterial wilt symptoms for the endophyte CASJ009 and the pathogens CASJ001, NCPPB382, and CASJ002 7 days postinoculation (dpi). B, Wilt and canker disease symptoms on tomato leaves and stems mockinoculated and infected with CASJ001 and CASJ001 $\mathrm{p}$ CM1 7 dpi. Tomato stems (Solanum lycopersicum cv. Early Pak 7) were stabbed with a needle and were inoculated with $5 \mu \mathrm{l}$ of Clavibacter michiganensis subsp. michiganensis at $10^{7} \mathrm{CFU}$ per milliliter. Strains were dilution-plated at day 0 to verify equal inoculation concentrations. CASJ001 $\Delta$ pCM1 did not cause disease symptoms 7 dpi. C, Representative disease symptoms in CASJ002, CASJ002 $\Delta$ pCM2, and $\mathrm{CASJ} 002 \Delta \mathrm{pCM} 1 \Delta \mathrm{pCM} 2$ at $7 \mathrm{dpi}$. Inoculations were performed as described in B. D, Bacterial titers in stem tissue $7 \mathrm{dpi}$ with CASJ002 and CASJ002 2 pCM2. Inoculations were performed as described in (B). Stem sections were taken $1 \mathrm{~cm}$ above the inoculation point to determine bacterial titers. Significant differences were detected by a two-tailed $t$ test, $P<0.001$. E, Bacterial titers in stem tissue 7 dpi with CASJ002, CASJ002 $\Delta$ pCM1, and CASJ002 $\Delta$ pCM1pCM2. No significant differences were detected between treatments (Tukey's honest significant difference, $P<0.05$ ). 
tomato. Experiments focused on two C. michiganensis subsp. michiganensis strains: CASJ001, which only possesses a pCM1-like plasmid, and CASJ002, which possesses pCM1- and pCM2-like plasmids (Table 1). We cured pCM1 from CASJ001 (CASJ001 1 p1), pCM2 from CASJ002 (CASJ002_p2), and both plasmids from CASJ002 (CASJ002 $\Delta \mathrm{p} 1 \Delta 2$ ). The plasmid status of these strains was confirmed by polymerase chain reaction (PCR) and their differential capacity to degrade cellulose.

The plasmid-cured strains were inoculated onto tomato stems, and disease symptoms as well as bacterial titers were analyzed at $7 \mathrm{dpi}$. The plasmid-cured derivatives CASJ001 $\Delta \mathrm{p} 1$ and CASJ002 $\Delta \mathrm{p} 1 \Delta 2$ failed to induce bacterial canker symptoms on tomato, indicating the essential role of $\mathrm{pCM}-1$ in pathogenicity (Fig. 3B and C). Bacterial titers of CASJ001 $\Delta$ p1 were significantly lower (fivefold) compared with the wild-type CASJ001 strain (Fig. 3D), although CASJ001 $\Delta$ p1 was still able to multiply in planta and reach relatively high titers (Fig. 3D). In contrast, the bacterial titers of CASJ002, CASJ002 $\Delta$ p2, and CASJ002 $\Delta$ p1 $\Delta 2$ were not significantly different (Fig. 3E). Curing pCM2 from CASJ002 significantly decreased wilting symptoms and rendered this strain weakly pathogenic (Fig. 3E). This indicated that pCM2 is important for the virulence of this strain. Together, these results demonstrate the essential role of pCM1 in pathogenicity and a differential role of pCM2 plasmids that is strain-dependent. In both CASJ002 and NCPBB382, pCM2 significantly enhances pathogenicity. However, pCM2 is absent in CASJ001 and this strain is able to grow to high titers and cause typical bacterial canker disease symptoms, indicating that pCM2 is not always essential for pathogenicity (Figs. 1 and 3).

The CelA cellulase is present in pCM1-like plasmids and was conserved in all the sequenced $C$. michiganensis subsp. michiganensis strains. Hence, we sought to investigate the capacity of $\mathrm{celA}$ to complement pathogenicity of the plasmid-cured derivatives of CASJ001 and CASJ002. CelA was cloned into the pHN216 vector, which stably replicates in Clavibacter spp. (Laine et al. 1996). pHN216 carrying celA was transformed into CASJ001 $1 \mathrm{p} 1$ and CASJ002 $\Delta \mathrm{p} 1 \Delta \mathrm{p} 2$. The presence of celA in CASJ001 $\Delta \mathrm{p} 1$ partially restored pathogenicity, but the symptoms were not as severe as the wild-type strain (Fig. 4A). Bacterial growth in the celA CASJ001 $\Delta$ p1 complemented strain was not significantly different compared with CASJ001 $\Delta \mathrm{p} 1(\mathrm{EV})$ (Fig. 4B). The presence of celA in CASJ002 $\Delta \mathrm{p} 1 \Delta \mathrm{p} 2$ also partially restored pathogenicity in this strain lacking both pCM1 and pCM2, with the development of wilt and canker symptoms (Fig. 4C). However, there was no significant difference in bacterial titers in planta in comparison with wild-type CASJ002 (Fig. 4D). It is striking that a single gene, celA, partially restored pathogenicity of the plasmid-cured CASJ001 $\Delta \mathrm{p} 1$ and CASJ002 $\Delta \mathrm{p} 1 \Delta \mathrm{p} 2$ and further supports the critical role this cellulose plays in bacterial canker disease.

\section{Prediction and analyses of secreted Clavibacter proteins.}

During infection, many pathogens secrete proteins, termed effectors, that are collectively required for virulence (Dou and Zhou 2012; Toruño et al. 2016). Gram-negative plant pathogenic bacteria inject effectors into plant cells via the T3SS. However, C. michiganensis subsp. michiganensis is a gram-positive bacterium and, thus, does not possess a T3SS, nor is there evidence that there is an alternative mechanism to secrete effectors directly into host cells (Chang et al. 2014). C. michiganensis subsp. michiganensis does possess general secretory pathway (Sec) and twin arginine translocation (Tat) systems for protein transport across the cell membrane and wall (Chang et al. 2014). Identification and functional annotation of a pathogen's secretome are particularly helpful for detecting potential virulence factors. We predicted the Sec and Tat secretomes in all the C. michiganensis subsp. michiganensis strains sequenced in the present study in addition to the reference genome NCPPB382. Note that lipoproteins or other proteins predicted to be anchored to the bacterial cell were not included.

The number of Sec-dependent secreted proteins in C. michiganensis subsp. michiganensis genomes ranged from 62 to 89 (Fig. 5A), whereas Tat-dependent proteins ranged from 32 to 44 (Fig. 5B). Interestingly, CASJ007 and CASJ001, which both lack the pCM2 plasmid, possess very similar Sec and Tat secretomes. Thirteen core Sec-dependent proteins were identified in all the sequenced $C$. michiganensis subsp. michiganensis strains (Supplementary Table S4). In order to determine if these core proteins are conserved in $C$. michiganensis subsp. michiganensis and tomato endophytes, we performed clustering analyses based on sequence identity using CD-HIT software with an identity threshold set to $95 \%$ ( $\mathrm{Li}$ and Godzik 2006). There was little overlap in the secretome of C. michiganensis subsp. michiganensis and endophytic Clavibacter strains. With respect to Sec secreted proteins, the number of homologous proteins shared between C. michiganensis subsp. michiganensis and endophytes ranged from one to nine (Fig. 5A). Similarly, few Tat-dependent proteins were shared between $C$. michiganensis subsp. michiganensis and endophytes (Fig. 5B).

The function of Sec and Tat secreted proteins were predicted using InterProScan (Quevillon et al. 2005). Most of the Sec secreted proteins were predicted $\alpha / \beta$-hydrolases, peptidases, and carbohydrate-degrading enzymes (Fig. 5C). The Sec secreted proteins also included lipolytic enzymes, cutinases, peptidoglycan binding proteins, and pectate lyases (Fig. 5C). The Tat secreted proteins included carboxypeptidases, Dyp type peroxidases, and some carbohydrate-degrading enzymes (Fig. 5D). These analyses indicate that $C$. michiganensis subsp. michiganensis strains secretes a wide range of proteins during infection. These secreted proteins include a range of degradative enzymes that could alter host physiology and facilitate colonization as well as degrade the host cell wall to provide nutrients and manipulate defense responses.

\section{Annotation of carbohydrate-active enzymes (CAZymes) in Clavibacter.}

CAZymes are involved in the degradation and metabolism of diverse glycoconjugates, oligosaccharides, and polysaccharides (Cantarel et al. 2009). Plant-pathogenic CAZymes have a central role in the ability to breakdown the plant cell wall and facilitate bacterial colonization and nutrient acquisition (Cantarel et al. 2009). To assess the capability of $C$. michiganensis subsp. michiganensis to degrade and metabolize different polysaccharides, all putative CAZymes present in each genome were identified based on similarity to signature domains present in the four catalytic classes of these proteins (Cantarel et al. 2009). Five percent (154 to 173) of C. michiganensis subsp. michiganensis genes encoded predicted CAZymes (Supplementary Fig. S4; Supplementary Table S5). The five tomato endophytic Clavibacter strains were also analyzed and had fewer total CAZymes (138 to 154). Comparison of glycoside hydrolases (GHs), glycosyltransferases, polysaccharide lyases (PLs), and carbohydrate esterases revealed that $C$. michiganensis subsp. michiganensis exhibits substantial variation in CAZyme classes when compared with endophytes and pathogenic Clavibacter subspecies (Supplementary Table S6). Furthermore, there was a higher overall number of CAZymes in $C$. michiganensis subsp. michiganensis compared with other pathogenic $C$. michiganensis subspecies. These differences may reflect the host specificity of different C. michiganensis subspecies as well as the tomato endophytes that are pathogenic on other hosts.

Plant PCWDEs are a subset of CAZymes produced by plant pathogens to degrade plant cell walls (Cantarel et al. 2009). Plants possess primary and secondary cell walls that serve as a structural 
barrier. Specific classes of CAZymes are involved in degrading cellulose, hemicellulose, xylans, and pectins in the plant cell walls. We compared the PCWDEs found in C. michiganensis subsp. michiganensis strains with other $C$. michiganensis subspecies and xylem-restricted bacteria with different host specificities. Interestingly, C. michiganensis subsp. michiganensis has a greater number of PCWDEs (Fig. 6). Overall, the GH1 and GH3 families, which have members that are able to degrade cellulose, were most abundant in $C$. michiganensis subsp. michiganensis. Four copies of GH1 were found in each $C$. michiganensis subsp. michiganensis genome, whereas zero to two copies were present in the other analyzed bacteria (Fig. 6). Each C. michiganensis subsp. michiganensis strain possessed a minimum of eight $\mathrm{GH} 3$ members, whereas other $C$. michiganensis subspecies and tomato endophytes had no more than four (Fig. 6). Proteins involved in hemicellulose decomposition (GH31, GH35) were more commonly found in the $C$. michiganensis subsp. michiganensis genome (Fig. 6). GH43, which encodes for endo$1,4-\beta$-xylanases, was found in all $C$. michiganensis subsp. michiganensis strains as well as C. michiganensis subsp. sepedonicus and the endophyte CASJ009 (Fig. 6). However, GH43 members were not found in any other Clavibacter genomes (Fig. 6). Multiple classes of PLs degrade pectin (Abbott and Boraston 2008). Interestingly, PL3 was the only PL family present in C. michiganensis subsp. michiganensis strains, and most of the pathogenic $C$. michiganensis subsp. michiganensis strains contained two copies. The genomes of CASJ009, C. michiganensis subsp. sepedonicus and $C$. michiganensis subsp. tessellarius contained one copy of PL3, whereas it was absent in all other
Clavibacter species and xylem-restricted bacteria. Based on their overall arsenal of CAZymes, C. michiganensis subsp. michiganensis seems to possess unique capabilities to break down and metabolize different types of tomato cell-wall components, consistent with a lifestyle in the vasculature of this host plant.

\section{Glycome profiling reveals differences in tomato cell-wall chemistry after infection.}

To investigate the ability of $C$. michiganensis subsp. michiganensis to break down and metabolize different types of plant cellwall material, glycome profiling was performed. Glycome profiling employs an enzyme-linked immunoabsorbent assay (ELISA), using 149 monoclonal antibodies recognizing diverse epitopes in plant cell-wall matrix polymers to evaluate cell-wall composition (Pattathil et al. 2012).To identify differences in overall composition and extractability of major noncellulosic cell-wall glycans, glycome profiling was performed on tomato stem segments 14 dpi with C. michiganensis subsp. michiganensis CASJ002, the tomato endophyte CASJ009, and an uninfected control. Cell-wall extracts were prepared using increasingly harsh reagents (ammonium oxalate, sodium carbonate, $1 \mathrm{M} \mathrm{KOH}$, and $4 \mathrm{M} \mathrm{KOH}$ ), and glycome profiles were generated after pooling three biological replicates from each treatment.

Overall, glycome profiles revealed clear differences among treatments, demonstrating that cell walls are affected in a significant way after infection (Fig. 7; Supplementary Table S7). The most striking differences (Fig. 7, outlined with white boxes) were observed in the $1 \mathrm{M} \mathrm{KOH}$ extract. In plants infected with C. michiganensis subsp. michiganensis CASJ002, the most notable
A

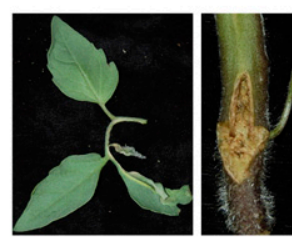

Pathogenicity: Pathogen Strain: CASJ001 Plasmids: $\mathrm{pCM} 1$

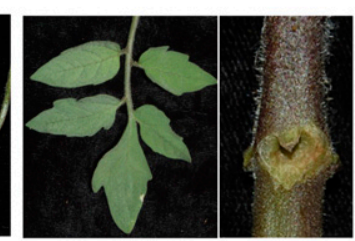

Non-pathogenic CASJ001 $\triangle \mathrm{p} 1$ pHN16(EV)

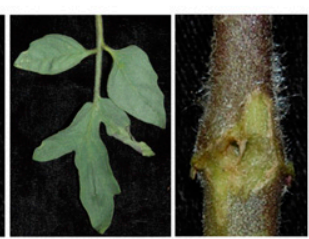

Weakly pathogenic CASJ001 $1 \mathrm{p} 1$ pHN16(celA)

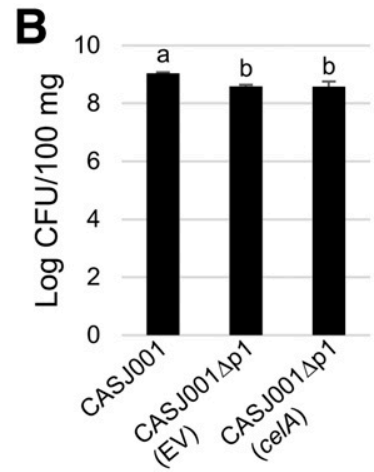

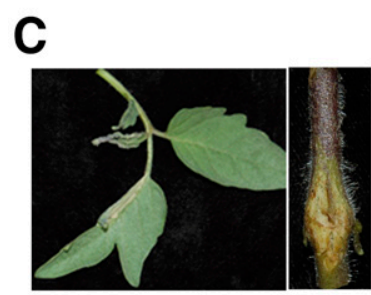

Pathogenicity: Pathogen Strain: CASJ002 Plasmids: $\mathrm{pCM} 1$ \& $\mathrm{pCM} 2$

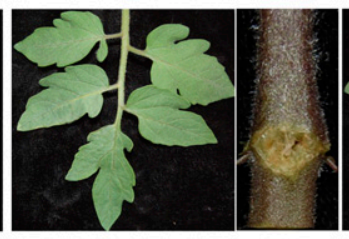

Non-pathogenic CASJ002 $\Delta \mathrm{p} 1$ $\triangle \mathrm{p} 2(\mathrm{EV})$
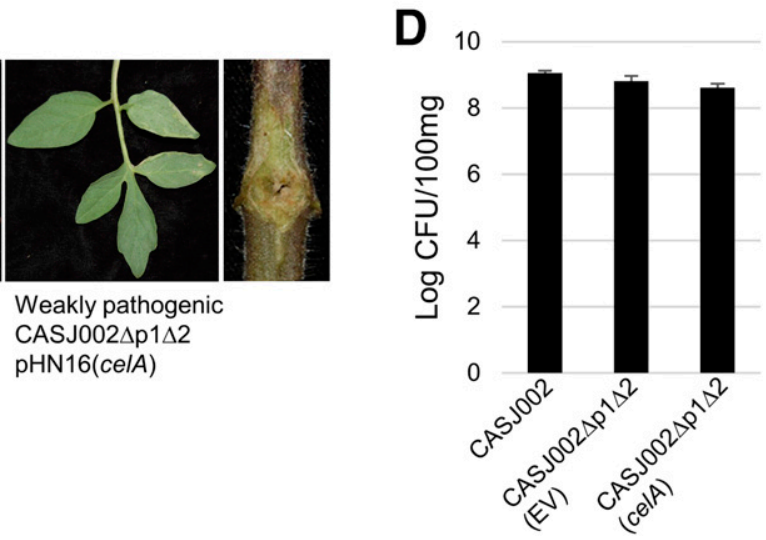

Fig. 4. The celA gene can partially complement Clavibacter michiganensis subsp. michiganensis virulence in plasmid-cured strains. A, Bacterial canker disease symptoms in tomato leaves and stems infected with CASJ001 $\triangle \mathrm{pCM} 1$, CASJ001 $\Delta \mathrm{pCM} 1$ carrying the vector pHN16(EV), and CASJ001 $1 \mathrm{pCM} 1 \mathrm{carrying}$ pHN16 with celA at 7 days postinoculation (dpi). Tomato stems (Solanum lycopersicum $\mathrm{cv}$. Early Pak 7) were stabbed with a needle and were inoculated with 5 $\mu \mathrm{l}$ of $C$. michiganensis subsp. michiganensis at $10^{7} \mathrm{CFU}$ per milliliter. CASJ001 $\triangle \mathrm{pCM} 1$ is unable to cause disease symptoms. B, Bacterial titers in stem tissue 7 dpi with strains described in A. Inoculations were performed as described in A. Stem sections were taken $1 \mathrm{~cm}$ above the inoculation point to determine bacterial titers. Statistical differences were detected by Tukey's honest significant difference, $P<0.05, n=18$. C, Representative disease symptoms in CASJ002, CASJ002 $\triangle \mathrm{pCM} 1 \triangle \mathrm{pCM} 2(\mathrm{EV})$, and CASJ002 $\triangle \mathrm{pCM} 1 \triangle \mathrm{pCM} 2 \mathrm{pHN} 16$ (celA) at 7 dpi. Inoculations were performed as described in A. D, Bacterial titers in stem tissue $7 \mathrm{dpi}$ with strains described in C. Inoculations and statistical analyses were performed as described above. 
effect observed was a reduction in the amounts of diverse arabinogalactan epitopes in the $1 \mathrm{M} \mathrm{KOH}$ extracts. Here, the pectic arabinogalactan epitopes (RG-I/AG) were almost completely absent from the $1 \mathrm{M} \mathrm{KOH}$ extract, as were several other AG epitopes (AG-3 and AG-4). Other changes observed in the glycome profiles reflected more a change in epitope extractability rather than epitope removal. For example, there appeared to be higher levels of RG-I backbone epitopes and diverse xylan epitopes (Xylan 3-7) in the $1 \mathrm{M} \mathrm{KOH}$ extracts from $C$. michiganensis subsp. michiganensis-infected plants, as compared with plants colonized with the endophyte and uninfected controls. Furthermore, trace amounts of xyloglucan epitopes (nonfuc XG 1-6 and fuc XG monoclonal antibodie [mAbs]) were detected in the $1 \mathrm{M} \mathrm{KOH}$ extract, which indicates some loosening of xyloglucan epitopes from the plant cell wall after infection. Uninfected control plants showed the highest overall abundance of epitopes in the glycome profiles, further suggesting that infection leads to actual degradation of wall structures. This is substantiated by the trends in the amounts of extracted carbohydrates (Fig. 7, top bar graphs). These results clearly demonstrate severe modification of cell-wall integrity and architecture in tomato plants infected with $C$. michiganensis subsp. michiganensis CASJ002 compared with endophytic CASJ009 and control treatments.

\section{The pelA1 pectate lyase is important}

for symptom development.

Multiple Sec and Tat secreted proteins were predicted to be CAZYmes. The chp/tomA cluster contains many virulence genes essential for effective colonization, which includes secreted proteases and CAZYmes (Fig. 8A). The chp/tomA cluster is conserved among $C$. michiganensis subsp. michiganensis strains, and several core effectors are present in this GI. Our investigation of glycome profiles revealed significant differences in tomato cellwall composition upon infection with $C$. michiganensis subsp. michiganensis (CASJ002). In order to gain a greater understanding
A

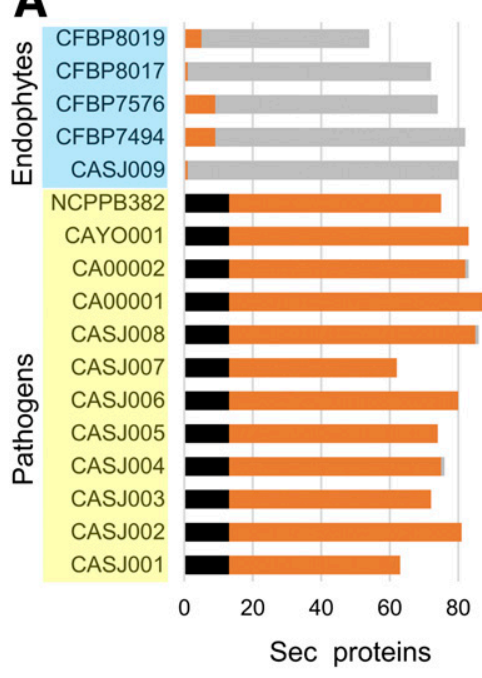

100

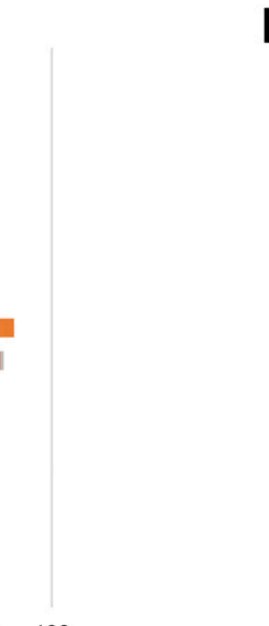

Present only in Endophytes

Variable secretomes

- Core pathogenic secretome

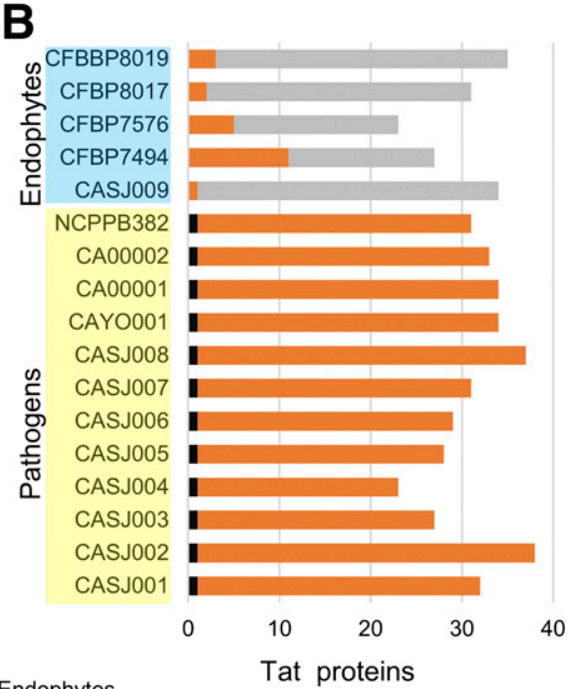

Tat proteins
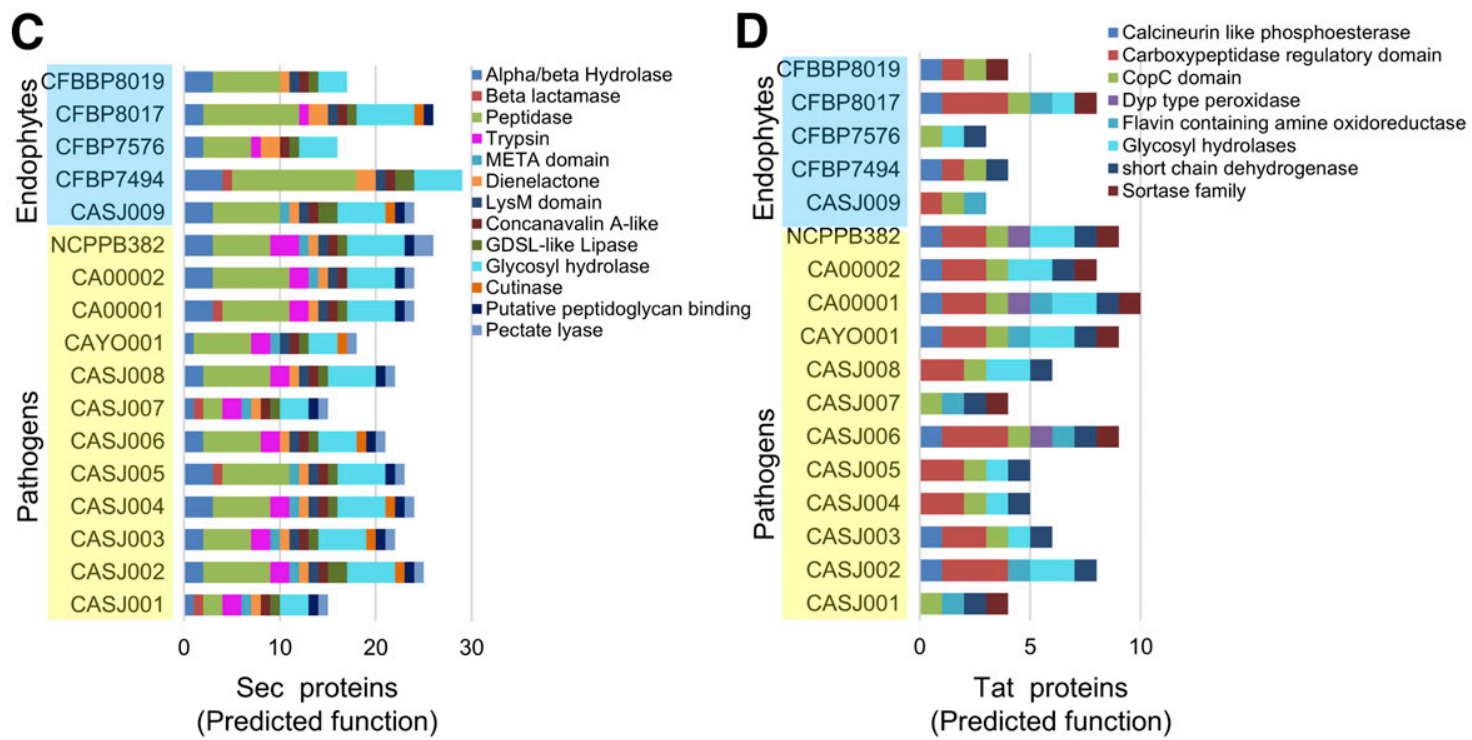

Fig. 5. Prediction of the Clavibacter secretome. A and B, General secretory pathway (Sec)-secreted and twin arginine translocation (Tat)-secreted effectors were predicted from genome sequences and were analyzed for their conservation across strains. Identified proteins were subsequently scanned for the presence of transmembrane regions and lipoproteins. Predicted transmembrane and lipoproteins were removed. C and D, Functional annotation of Sec- and Tat-secreted effectors performed using InterProScan. Representation of predicted function of Sec- and Tat-secreted proteins. 
of the importance of individual PCWDE members, we investigated the roles of two pectate lyases belonging to the PL3 family. Within the chp/tomA GI, there are two highly conserved genes, with homology to pectate lyases pelA1 and pelA2, that are predicted to be secreted by the Sec system (Fig. 8A). We deleted each of these genes to generate $\triangle p e l A 1$ and $\triangle p e l A 2$ in C. michiganensis subsp. michiganensis CASJ002. Two independent deletions were generated and analyzed for each gene, with deletion of each gene verified by PCR and DNA sequencing. Three-week-old tomato plants were inoculated with wild-type $C$. michiganensis subsp. michiganensis CASJ002, CASJ002_pelA1, and CASJ002_pelA2. Development of disease symptoms was monitored up to $14 \mathrm{dpi}$. Plants infected with CASJ002_pelAl exhibited a reduction in wilting, compared with plants infected with wild-type CASJ002 (Fig. 8B). In contrast, disease symptoms induced by CASJ002 $\Delta$ pelA2 were indistinguishable from those induced by wild-type CASJ002 (Fig. 8B). To examine the ability of CASJ002 2 pelA1 and CASJ002 $\Delta$ pelA2 to grow in planta, bacterial titers were determined in tomato plants 14 dpi. Bacterial titers were not significantly different among CASJ002, CASJ002_pelA1, or CASJ002_pelA2 (Fig. 8C).

Given the high degree of amino acid similarity between the two proteins (90\%), it was unexpected that deletion of pelAl but

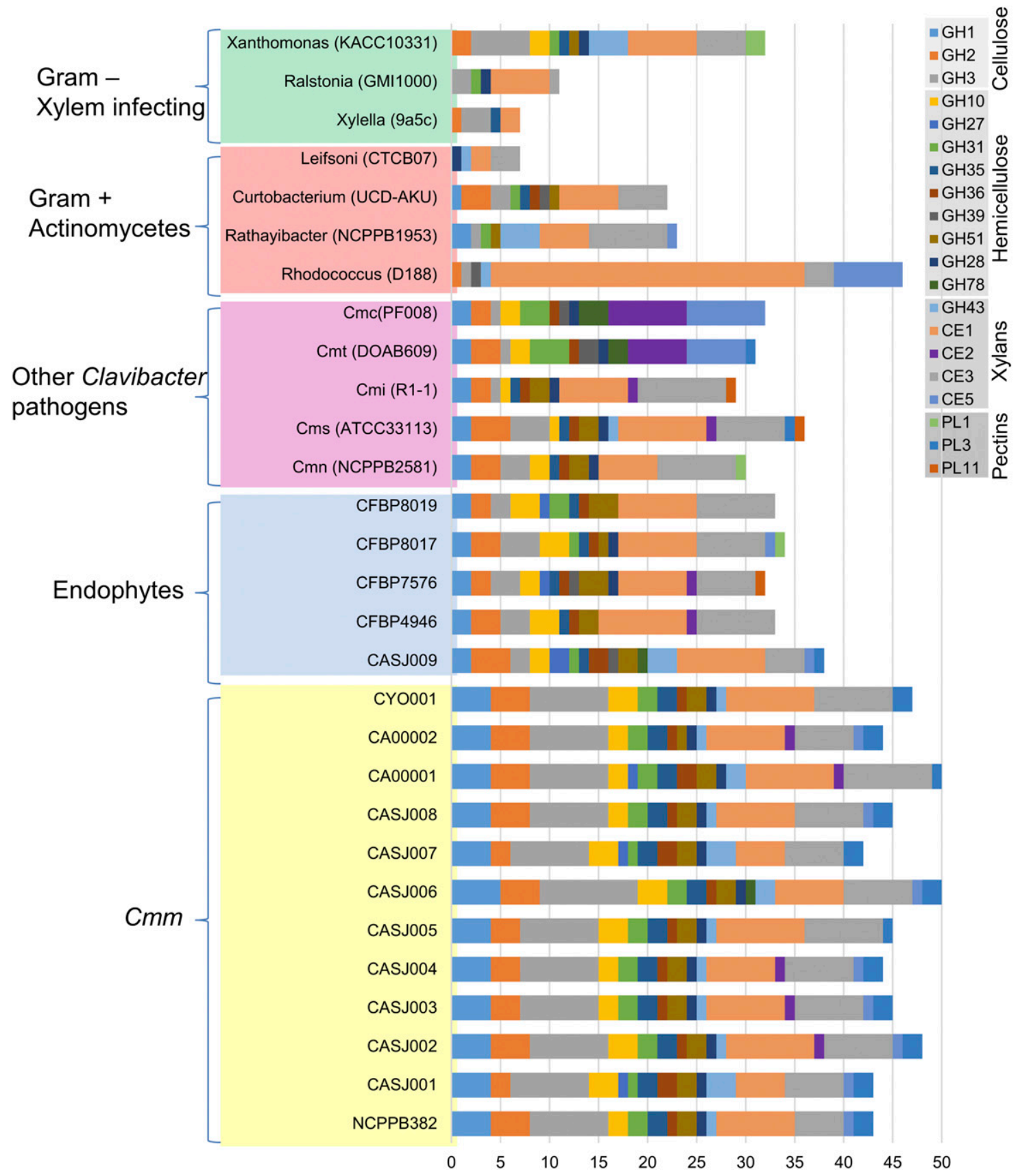

Fig. 6. Comparison of plant cell wall-degrading enzymes (PCWDEs) across Clavibacter spp., related gram-positive bacteria, and other xylem-colonizing bacteria. Pathogenic C. michiganensis subsp. michiganensis, five endophytes, five Clavibacter michiganensis strains pathogenic on plants other than tomato, four gram-positive actinomytes, and three gram-negative xylem-infecting pathogens were analyzed. Families of PCWDEs are grouped based on their major targeted substrates including cellulose, hemicellulose, xylans, and pectin (gray blocks in the right). $\mathrm{GH}=$ glycoside hydrolases, $\mathrm{CE}=$ carbohydrate esterase, and $\mathrm{PL}=$ polysaccharide lyase. The stacked bar charts indicate different types of PCWDEs in different strains. On the left are bacterial strains, gram-positive xylem-infecting bacteria, other pathogenic Clavibacter subspecies, endophytic Clavibacter strains, and C. michiganensis subsp. michiganensis. 
not pelA2 reduced disease symptom severity. To gain a greater understanding of this phenomenon, we investigated the expression of pelA1 and pelA2. CASJ002 was grown in rich Luria broth (LB) medium to midexponential phase and was then transferred to M9 minimal media. Total RNA was extracted and expression of pelA1 and pelA2 was monitored by quantitative PCR. Consistent with a role in pathogen virulence in planta, pelAl expression was significantly higher than that of pelA2

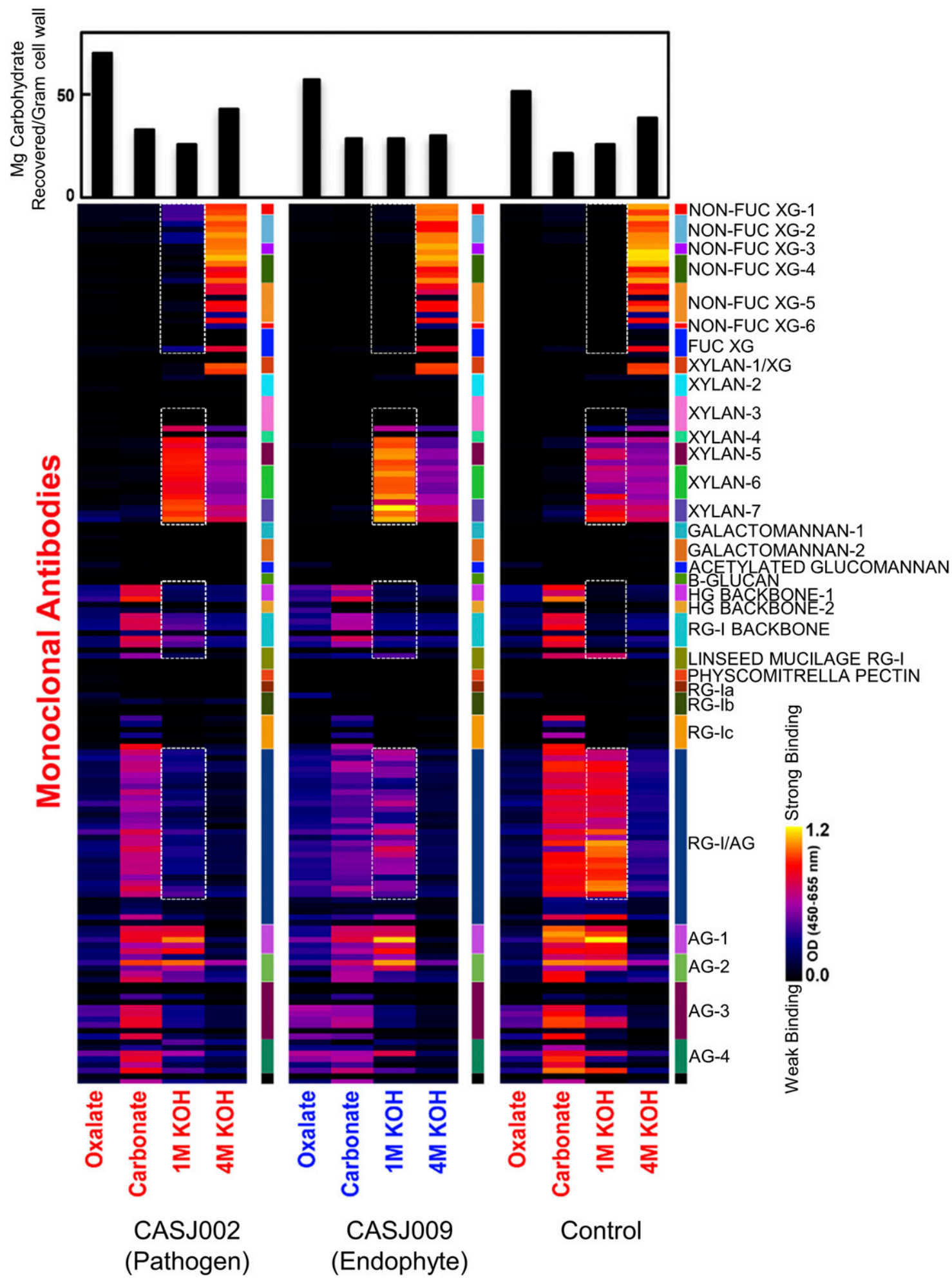

Fig. 7. Glycome profiling reveals extensive disruption of tomato cell-wall components after Clavibacter infection. Tomato stems (Solanum lycopersicum cv. Early Pak 7) were stabbed with a needle and were inoculated with $5 \mu$ of Clavibacter CASJ002 and CASJ009 at $10^{7}$ CFU per milliliter. Glycome profiling was performed on tomato stems 14 days postinoculation. The enzyme-linked immunoabsorbent assay (ELISA) response values (with background values subtracted from the mean value of two technical replicates) are represented as heat maps. The monoclonal antibodies are grouped based on the cell-wall glycans they detect, as depicted in the panel at the right of the heat map. The gravimetric amounts of carbohydrate materials extracted from the walls by each extraction reagent are shown as bar graphs at the top of the figure. CASJ002 = pathogenic C. michiganensis subsp. michiganensis, CASJ009= endophytic Clavibacter spp. isolated from a tomato plant with bacterial canker symptoms in California; control = no infection. 
in M9 minimal media (Fig. 8D). We also examined pelA1 and pelA2 expression in C. michiganensis subsp. michiganensis NCPPB382 and CA00002 and observed similar results (Supplementary Fig. S5). These data revealed similar expression patterns of the pelA1 CAZyme across diverse $C$. michiganensis subsp. michiganensis strains as well as another level of complexity in C. michiganensis subsp. michiganensis virulence, i.e., different levels of virulence gene expression.

\section{DISCUSSION}

Bacterial canker of tomato is a disease of worldwide importance, particularly in greenhouse production and in regions with Mediterranean and temperate climates, e.g., processing tomato production in California (de León et al. 2011; Sen et al. 2015). Outbreaks of bacterial canker can be devastating, but, like many diseases, tend to occur sporadically (de León et al. 2011).
Here, we utilized recent advancements in genome sequencing and long-read technology to obtain high-quality genomes for multiple pathogenic $C$. michiganensis subsp. michiganensis strains collected at different times and in different geographical locations in California as well as for Clavibacter strains that are endophytes in tomato. The 11 C. michiganensis subsp. michiganensis strains isolated from tomato plants with bacterial canker symptoms from commercial production fields in California in different years and geographical locations were placed in a single clade with other C. michiganensis subsp. michiganensis strains from worldwide locations is consistent with the monophyletic nature of this pathogen. However, the finding that the California $C$. michiganensis subsp. michiganensis strains were not clonal and exhibited a high degree of genetic diversity when compared with each other and other $C$. michiganensis subsp. michiganensis strains is in agreement with recent studies showing considerable genetic diversity in $C$. michiganensis subsp. michiganensis strains from various

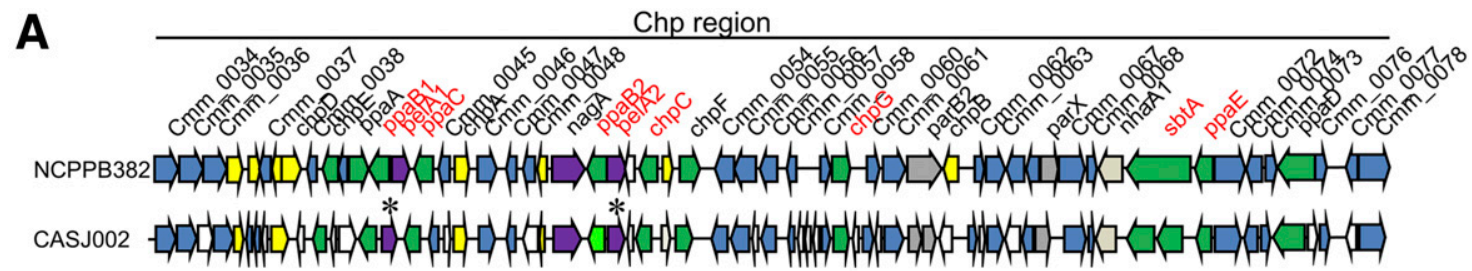

CASJ009 마

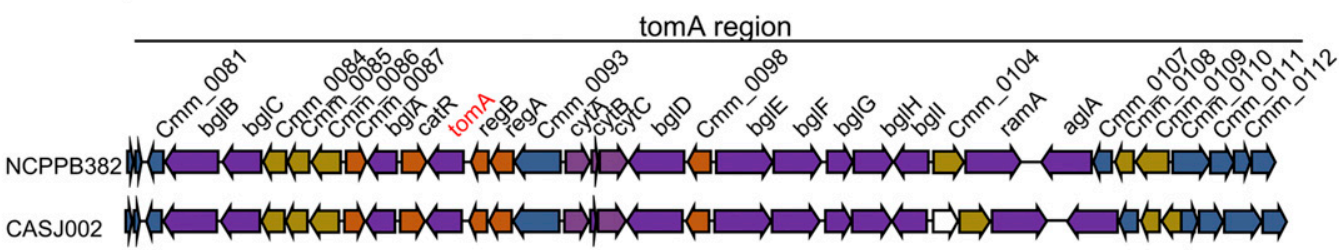

CASJ009

B

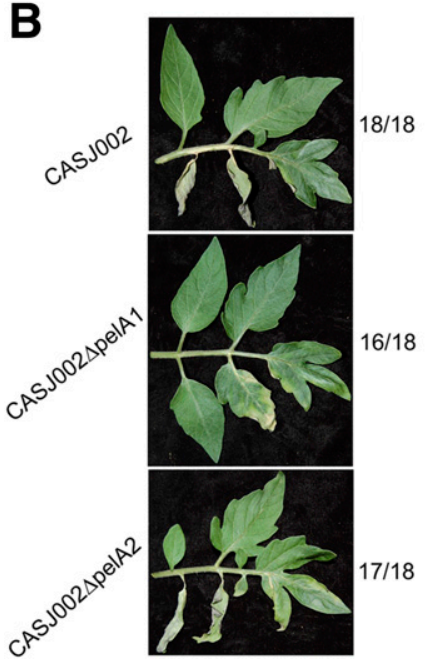

$\mathbf{C}_{12}$

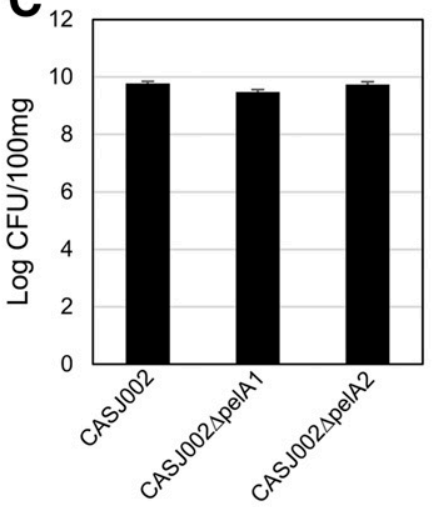

w serine proteases

regulators

transporters

- CAZYmes

Pseudogenes

D

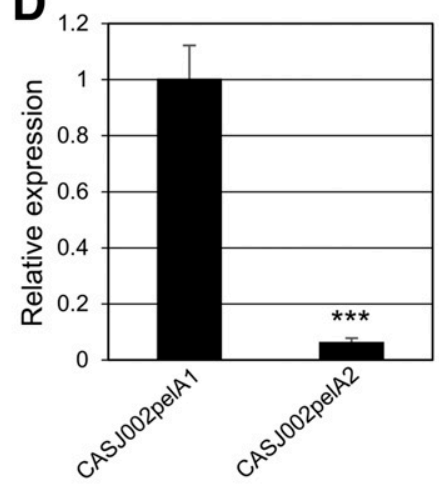

Fig. 8. Deletion of the PelA1 pectate lyase but not PelA2 decreases bacterial virulence. A, Chp/tomA is present in all pathogenic Clavibacter michiganensis subsp. michiganensis but is absent in endophytic Clavibacter strains. Gene content in the chp/tomA pathogenicity island of CASJ002 and NCPPB382. Top panel, chp cluster and bottom panel, tomA cluster. B, Unilateral wilting symptoms in infected tomato plants (Solanum lycopersicum cv. Early Pak 7) 14 days

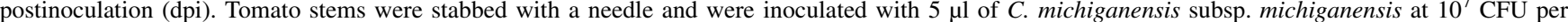
milliliter. Strains were dilution-plated at day 0 to verify equal inoculation concentrations. The fraction on the side of each image indicates the number of plants with similar disease symptoms relative to the 18 inoculated plants. The pelA1 deletion exhibits decreased disease symptoms. C, Bacterial titers of wild-type C. michiganensis subsp. michiganensis compared with the pelA1 and pelA2 deletions 14 dpi. Plants were inoculated as described in B. No significant differences were detected, using Tukey's honest significant difference, $P<0.05, n=18$. D, Expression of pelA1 and pelA2 by quantitative polymerase chain reaction. C. michiganensis subsp. michiganensis CASJ002 was grown in M9 mimicking media, RNA was extracted, and gene expression was normalized to the ITS gene. Significant differences were detected by a two-tailed $t$ test, $P<0.001$. 
geographical regions (Jacques et al. 2012; Milijašević-Marčić et al. 2012; Quesada-Ocampo et al. 2012; Tancos et al. 2015). Thus, the California C. michiganensis subsp. michiganensis strains likely represent multiple introductions over time, most likely via contaminated seed.

Moreover, the endophytic Clavibacter strains exhibited even more genetic diversity than the $C$. michiganensis subsp. michiganensis strains, with three strains, CFPB7494, CFBP8017, and CFBP7576, placed in monophyletic clades with $C$. michiganensis subspecies pathogenic on alfalfa, wheat, and pepper, respectively. Evidence that some of the tomato endophytes are strains of pathogenic subspecies came from the finding that CFBP7494 and CFBP7576 caused disease on wheat and pepper, respectively. Thus, these Clavibacter strains are pathogenic on other plant species but are capable of colonizing tomato as endophytes. This finding reveals an additional mechanism by which plant pathogenic $C$. michiganensis subspecies can be disseminated, i.e., as endophytes associated with nonhost plants. The ability to colonize plants as a symptomless endophyte on one plant species but act as a pathogen on other plant species has been observed in several pathogenic fungi (Barnes and Shaw 2003; Ploch and Thines 2011; Sowley et al. 2010) and bacteria (Darrasse et al. 2010).

The reference strain $C$. michiganensis subsp. michiganensis NCPPB382 carries the pCM1 and pCM2 plasmids, which are both required for wilting and canker formation (Dreier et al. 1997; Chalupowicz et al. 2012; Meletzus et al. 1993). C. michiganensis subsp. sepedonicus is unable to infect and cause disease in tomato but is able to infect another solanaceous plant, potato, causing bacterial ring rot disease. Whereas the chromosomes of $C$. michiganensis subsp. michiganensis NCPPB382 and C. michiganensis subsp. sepedonicus ATCC33113 exhibit significant similarity, there are clear differences in their plasmid composition (Bentley et al. 2008; Brown et al. 2002; Eichenlaub and Gartemann 2011; Mogen and Oleson 1987). The plasmid-free derivative of $C$. michiganensis subsp. michiganensis NCPPB382 causes localized lesions but not systemic disease symptoms in tomato (Chalupowicz et al. 2017). Thus, plasmid composition may play an important role in $C$. michiganensis host specificity and the type of disease symptoms induced. All C. michiganensis subsp. michiganensis strains sequenced in the present study possessed a pCM1-like plasmid, whereas two strains lacked the pCM2 plasmid and retained pathogenicity on tomato. Curing of pCM1 from C. michiganensis subsp. michiganensis CASJ001 and CASJ002 rendered these strains unable to cause disease, which is fully consistent with the essential role for the pCM1 plasmid in induction of disease symptoms and bacterial virulence. In contrast, curing of pCM2 reduced but did not abolish virulence and, taken together with the finding that two pathogenic California $C$. michiganensis subsp. michiganensis strains lacked pCM2, indicates that this plasmid is not essential for virulence. Stress conditions can induce C. michiganensis subsp. michiganensis plasmid loss, and the pCM1/pCM2 plasmids are conjugative (Gartemann et al. 2003; Meletzus et al. 1993). This may partly explain the diversity of the plasmid profiles found for the California $C$. michiganensis subsp. michiganensis strains and the possibility that endophytic Clavibacter species or strains could be rendered pathogenic through acquisition of pCM1 or pCM2.

The capacity of $C$. michiganensis subsp. michiganensis to cause bacterial canker disease symptoms and to grow as an epiphyte in tomato plants can be uncoupled. The plasmid-free derivative CASJ001 $\Delta \mathrm{p} 1 \Delta \mathrm{p} 2$ no longer induced disease symptoms in tomato without a corresponding decrease in bacterial growth. The secreted endocellulase $c e l A$, present in all pCM1like plasmids, partially restored pathogenicity but not bacterial titers of CASJ001 $\Delta$ p1, possibly indicating a role for other genes on the pCM1 plasmid. Disease symptoms and bacterial growth were also uncoupled in NCBBP382 in multiple cases, including plasmid cured derivatives, complementation of pCM1 with a large DNA fragment containing celA, and deletions of the vatrl and vatr2 transcriptional regulators (Chalupowicz et al. 2012; Meletzus et al. 1993; Savidor et al. 2014). In other plant species, C. michiganensis subsp. michiganensis elicits cell death in some nonhost plants, consistent with the recognition of conserved microbial features or secreted pathogen proteins (Alarcón et al. 1998; Gitaitis 1990). In C. michiganensis subsp. michiganensis and C. michiganensis subsp. sepedonicus, some members of the secreted protease family pat-1 can induce cell death in nonhosts, indicating it might be recognized by the host defense system (Lu et al. 2015a; Nissinen et al. 2009; Stork et al. 2008). The observation that plasmid-free C. michiganensis subsp. michiganensis strains can act as endophytes in tomato suggests that presumed genes necessary for endophytic growth in tomato, e.g., for host recognition, colonization, and defense suppression, are chromosomally encoded.

Pathogens secrete a variety of effector proteins, and expression of effectors may occur spatially and temporally, depending on the stage of infection (Toruño et al. 2016). After entry into the plant, Clavibacter michiganensis strains systemically infect vascular tissue and, initially, have a biotrophic lifestyle (Eichenlaub and Gartemann 2011). The C. michiganensis subsp. michiganensis strains characterized in the present study exhibited significant differences in their secretomes compared with endophytic strains, indicating a degree of specialization with the tomato host. During later stages of disease, C. michiganensis subsp. michiganensis is an aggressive pathogen that induces formation of stem cankers and degradation of pith tissues (de León et al. 2011; Eichenlaub and Gartemann 2011). Secreted proteins included many CAZymes involved in plant cell-wall breakdown and metabolism of cell-wall components. Indeed, C. michiganensis subsp. michiganensis strains possessed more predicted CAZymes compared with other grampositive or xylem-limited bacterial plant pathogens. This higher number of CAZymes is consistent with C. michiganensis subsp. michiganensis inducing extensive tissue damage during later stages of disease. Using glycome profiling, we detected significant alterations of plant cell-wall glycans, particularly among diverse arabinogalactans, indicating severe modification of tomato cell-wall architecture during $C$. michiganensis subsp. michiganensis infection. The predicted pectate lyase CAZyme pelAl was also required for robust induction of wilting and canker symptoms, highlighting the importance of specific secreted degradative enzymes in the pathogenesis of $C$. michiganensis subsp. michiganensis.

In the last decade, rapid technological advances have facilitated the sequencing of many different organisms. Here, we used a combination of short- and long-read technologies to obtain highquality sequences of multiple Clavibacter genomes for subsequent comparative and functional analyses. We confirmed the importance of some virulence factors present in the $C$. michiganensis subsp. michiganensis NCPPB382 reference strain, such as pelAl, the chp/tomA GI, and the pCM1 plasmid. We also identified 13 core secreted proteins present in all pathogenic $C$. michiganensis subsp. michiganensis strains, which warrant future investigation for their contribution to pathogen virulence and represent promising targets for disease control. However, clear differences also were found among $C$. michiganensis subsp. michiganensis strains with respect to plasmid composition, bacterial aggressiveness, and gene content. This highlights the importance of comparative genomics and investigation of virulence mechanisms of various agriculturally relevant $C$. michiganensis subsp. michiganensis strains.

\section{MATERIALS AND METHODS}

Bacterial strains and plasmids.

The bacterial strains and plasmids used in this study are listed in Table 1 and Supplementary Table S1. C. michiganensis subsp. 
michiganensis strains were grown in tryptone broth with yeast (TBY), D2, C medium, sorbitol broth (SB) medium at $28^{\circ} \mathrm{C}$ (Kirchner et al. 2001), or minimal M9 medium (Chalupowicz et al. 2010). Escherichia coli strains (DH5 $\alpha$ and GM48) were grown in $\mathrm{LB}$ at $37^{\circ} \mathrm{C}$. The growth medium was supplemented with the antibiotics chloramphenicol $(20 \mu \mathrm{g} / \mathrm{ml}$ for $E$. coli and $10 \mu \mathrm{g} / \mathrm{ml}$ for $C$. michiganensis subsp. michiganensis), gentamicin $(100 \mu \mathrm{g} / \mathrm{ml}$ for $E$. coli and C. michiganensis subsp. michiganensis), and neomycin $(50 \mu \mathrm{g} / \mathrm{ml}$ for $E$. coli and $C$. michiganensis subsp. michiganensis), where necessary.

\section{Plant growth and pathogenicity assays.}

The tomato cultivar Early Pak No. 7 (EP-7) was used for all assays. Tomato plants were grown in a greenhouse at $23^{\circ} \mathrm{C}$ with a 14-h photoperiod and $70 \%$ relative humidity. All plant inoculations were performed with at least six biological replications and were repeated three times. Three- to four-week-old tomato plants were used for inoculation assays. C. michiganensis subsp. michiganensis strains were plated on TBY plates and were incubated for 2 to 3 days at $28^{\circ} \mathrm{C}$. Inoculum was prepared by diluting cells in $10 \mathrm{mM} \mathrm{MgCl}_{2}$ to a concentration of approximately $10^{7} \mathrm{CFU}$ per milliliter. Strains were dilution-plated at day 0 to confirm equal inoculum concentrations. Tomato plants were inoculated by stabbing the stem with a needle and pipetting $5 \mu$ of a $10^{7}-\mathrm{CFU} / \mathrm{ml}$ suspension of $C$. michiganensis subsp. michiganensis into the wound site. Plants were grown in the greenhouse as previously described (Thapa et al. 2015). To assess percent wilting after inoculation, plants were monitored every day for the appearance of wilting symptoms ( $n=18$ plants per strain). Disease symptoms were monitored for up to 14 days. Virulence was assessed by determining the number of plants that exhibited wilting symptoms 2 weeks postinoculation. For a plant to be rated as wilted, at least one leaflet had to exhibit unilateral or complete wilting. Wilting first appeared 5 dpi. Three-week-old pepper ('Numex Joe E Parker') and wheat plants ('Bobwhite') were inoculated as described above for tomato.

To determine bacterial titers in the tomato stem, 1-cm stem segments were cut $1 \mathrm{~cm}$ above and below the inoculation site at 7 and $14 \mathrm{dpi}$. To determine movement in tomato, samples were also collected 3, 6, and $9 \mathrm{~cm}$ above the infection site. Stem segments were surface-disinfected in $75 \%$ ethanol, the outer epidermis was removed, and the remaining segment was weighed and ground in $900 \mu \mathrm{l}$ of $10 \mathrm{mM} \mathrm{MgCl}_{2}$. Serial dilutions of the homogenate were plated on D2 medium (Kado and Heskett 1970) supplemented with $20 \mathrm{mg}$ of cycloheximide and were incubated for 4 to 6 days at $28^{\circ} \mathrm{C}$. Statistical differences between genotypes were detected using Tukey's honest significant difference $(P<0.05)$ or a twotailed $t$ test.

\section{Genomic DNA sequencing, assembly, and annotation.}

We sequenced the genomes of $11 C$. michiganensis subsp. michiganensis strains and one tomato endophyte (CASJ009) isolated from tomato plants with bacterial canker symptoms in fields in California from 1999 to 2011 (Table 1). Four endophytes from the French Collection for Plant-associated Bacteria (CFBP) culture collection were also included. Total genomic DNA was isolated with the Promega Wizard Genomic DNA purification kit (Promega, Madison, WI, U.S.A.) according to the manufacturer's instructions. For library construction for the Illumina platform, genomic DNA was sheared with a Covaris E220 sonicator, followed by end repair and phosphorylation. Fragmented DNA was used to construct paired-end libraries. Libraries were checked for size with a High-Sensitivity DNA kit (Agilent Technologies, Santa Clara, CA, U.S.A.) in the Bioanalyzer 2100, with an expected average size of $250 \mathrm{bp}$. Libraries were pooled and sequenced with paired-end reads on MiSeq and HiSeq 2500 systems (Illumina, San Diego, CA, U.S.A.). Seven Clavibacter strains were also sequenced with the Pacific Biosciences RSII sequencing platform (Pacific Biosciences, Menlo Park, CA, U.S.A.) (Table 1). Genomic DNA was prepared as a 20-kb library for P6-C4 chemistry, followed by BluePippin size selection at $15 \mathrm{~kb}$. Genome sequencing was performed at the Genome Center at the University of California Davis DNA Technologies Core Facility.

Genomes sequenced on Illumina were de novo assembled with the SPAdes (Bankevich et al. 2012) and the genomes sequenced on PacBio were de novo assembled with Hierarchical Genome Assembly Process 3 (Chin et al. 2013). The assembly with the highest assembly qualities in terms of N50 value and assembly size was selected and merged by the Mix pipeline, to obtain a consensus assembly for each species (Soueidan et al. 2013). The draft genomes were annotated with Prokka and the National Center for Biotechnology Information (NCBI) Prokaryotic Genome Annotation Pipeline (Seemann 2014; Tatusova et al. 2016).

\section{Phylogenetic analyses.}

We constructed a multigene tree of 59 Clavibacter isolates. Sequences for the maximum-likelihood MLSA tree were gathered from the NCBI nt and wgs databases as well as the strains sequenced in the present study, for six housekeeping genes ( $a t p D$, dnaK, gyrB, $p p K, r e c A$, and $r p o B)$. Alignments were produced with the PRANK alignment tool (Löytynoja and Goldman 2005). A maximum likelihood approach was used to construct the phylogenetic tree using MEGA software version 6 and a bootstrap analysis of 1,000 replicates (Tamura et al. 2013). The resulting phylogeny was visualized using iTOL (Letunic and Bork 2007).

Orthologous genes of 22 Clavibacter strains were predicted, using the OrthoMCL pipeline (Li et al. 2003). All-versus-all BLASTP $\left(E\right.$ value $<1 \times 10^{-5}$, alignment coverage $>50 \%$ ) comparison of all protein sequences for each species was performed, and orthologous genes were clustered by OrthoMCL. The normalized scores were fed into the MCL algorithm to classify the genes into predicted orthologous gene families with a default inflation parameter of 1.5. We performed multiple alignments of protein sequences with PRANK (Löytynoja and Goldman 2005). All the alignments were concatenated by FASconCAT, yielding a protein supermatrix (Kück and Meusemann 2010). A maximum likelihood approach was used to reconstruct the phylogenetic tree using RAxML software (Stamatakis 2006). The bootstrap was performed with 1,000 replicates. The resulting phylogeny was visualized using FigTree (version 1.4. 0).

\section{Bioinformatics analyses.}

Circularized genome visualization was performed with Circos version 0.69 (Krzywinski et al. 2009). GIs were detected using IslandViewer (Dhillon et al. 2015). IslandViewer integrates the sequence composition prediction methods IslandPath-DIMOB and SIGI-HMM as well as the single comparative GI prediction method IslandPick (Hsiao et al. 2005; Langille et al. 2008; Waack et al. 2006). CAZymes were identified with the Hmmscan program in the HMMER 3.0 package, using the family-specific hidden Markov model (HMM) profiles of CAZymes from the dbCAN database (Eddy 2009; Yin et al. 2012). Predicted protein sequences were screened for Sec and Tat signal peptides. Proteins possessing signal peptides for the Sec-dependent pathway were identified using the SignalP 3.0 server (Petersen et al. 2011). Proteins possessing signal peptides for the Tat secretory pathway were analyzed by TatP 1.0 (Bendtsen et al. 2005). Predicted lipoproteins and transmembrane proteins were filtered from the Sec and Tat secretomes. Transmembrane topology was predicted using TMHMM 2.0 (Sonnhammer et al. 1998). LipoP1.0 was used to predict lipoprotein signal sequence features (Juncker et al. 2003). 
Cell-wall extraction and glycome profiling.

C. michiganensis subsp. michiganensis strains were cultured for 2 to 3 days on TBY plates at $28^{\circ} \mathrm{C}$. Inoculum was prepared by diluting cells in $10 \mathrm{mM} \mathrm{MgCl} 2$ to a concentration of approximately $10^{7} \mathrm{CFU} / \mathrm{ml}$. Four-week-old tomato plants were inoculated by stabbing the stem with a needle and pipetting $5 \mu \mathrm{l}$ of a $10^{7}$ $\mathrm{CFU} / \mathrm{ml}$ suspension of buffer or Clavibacter strains CASJ002 and CASJ009 into the wound site. Stem samples above inoculation sites were collected 14 dpi. For each treatment, stem samples from 12 individual tomato plants were pooled for glycome profiling. Profiling was repeated twice with raw data. Alcohol-insoluble residues were prepared and glycome profiling were performed as described previously (Pattathil et al. 2012). Briefly, cell-wall extracts were prepared, using increasingly harsh reagents (ammonium oxalate, sodium carbonate, $1 \mathrm{M} \mathrm{KOH}, 4 \mathrm{M} \mathrm{KOH}$ ), and subsequent ELISA screening of these extracts was performed with a comprehensive suite of plant cell-wall glycan-directed mAbs (Pattathil et al. 2010). The mAbs were obtained from laboratory stocks (CCRC, JIM, and MAC series) at the Complex Carbohydrate Research Center (available through CarboSource Services) or from BioSupplies (Bundoora, Australia) (BG1, LAMP). Details about individual $\mathrm{mAbs}$ used for profiling are provided in Supplementary Table S8 and on the WallMabDB website.

\section{Recombinant DNA techniques.}

DNA manipulations and PCR were conducted according to standard protocols (Joseph and David 2001). Primers and primer sequences used for cloning and molecular assays are listed in Supplementary Table S2. For construction of the DpelA1 and $\triangle$ pelA2 deletion constructs, $1.5-\mathrm{kb}$ upstream and $1-\mathrm{kb}$ downstream regions flanking the pelA1 and pelA2 genes were PCR-amplified from C. michiganensis subsp. michiganensis CASJ002. PCR fragments were digested with HindIII and BamHI. Next, a 1.5$\mathrm{kb}$ fragment of the chloramphenicol cassette was digested with BamHI from the pEC70 plasmid (Tauch et al. 1998). The digested C. michiganensis subsp. michiganensis PCR fragments were ligated with the cmx fragment in the pUC19 vector with T4 DNA ligase. The pUC19pelA1 cmx and pUC19pelA2cmx were transformed into E.coli $(\mathrm{DH} 5 \alpha)$ and were selected on LB medium containing chloramphenicol $(10 \mu \mathrm{g} / \mathrm{ml})$. The presence of the cloned fragments in recombinant plasmids was confirmed by PCR and sequencing. The pUC19pelAlcmx and pUC19pelA2cmx DNA plasmids were extracted from $E$. coli $\mathrm{DH} 5 \alpha$ cells with Qiagen mini plasmid kits (Qiagen, Hilden, Germany). Plasmid DNA was then transformed into the nonmethylating E. coli GM48 (Palmer and Marinus 1994). The plasmids were extracted from E.coli GM48 cells and were subsequently electroporated into $C$. michiganensis subsp. michiganensis CASJ002. C. michiganensis subsp. michiganensis electrocompetent cells were prepared as previously described (Kirchner et al. 2001). Electroporation was performed with $100 \mu \mathrm{l}$ of competent cells and $1 \mu \mathrm{g}$ of the purified pUC19pelA $1 \mathrm{cmx}$ and pUC19pelA $2 \mathrm{cmx}$ in 0.1-cm electroporation cuvettes, using an Eppendorf electroporator model 2510 with the following settings: $12.5 \mathrm{Kv} / \mathrm{cm}$ (Table 1), $25 \mu \mathrm{F}$, and $600 \Omega$ with a time constant between 12 and $16 \mathrm{~ms}$. Cells were immediately mixed into SB medium and were regenerated for $3 \mathrm{~h}$ at $28^{\circ} \mathrm{C}$. Cells were spread onto SB agar plates containing chloramphenicol $(10 \mu \mathrm{g} / \mathrm{ml})$ and were incubated for 5 to 7 days. The presence of the $\triangle p e l A 1$ and $\triangle p e l A 2$ deletions in the selected transformant was confirmed by PCR and sequencing.

\section{Quantification of gene expression by quantitative reverse transcription (qRT)-PCR.}

C. michiganensis subsp. michiganensis strains were grown overnight in TBY medium and an aliquot was transferred into minimal media. Cells were harvested at optical densities between 0.35 and 0.55 . RNA was extracted from $5 \mathrm{ml}$ of the culture with Trizol reagent (Invitrogen, Carlsbad, CA, U.S.A.), according to the manufacturer's instructions. The total RNA was incubated for $30 \mathrm{~min}$ at $37^{\circ} \mathrm{C}$ with 10 units of DNase I (Promega) to remove residual genomic DNA. One microgram of total RNA was used to make cDNA (in a total volume of $20 \mu \mathrm{l}$ ) with M-MLV reverse transcription (Promega), using oligo $\mathrm{dT}_{18}$ primer. qRT-PCR was performed with a CFX96 touch real-time PCR detection system with the SsoFast EvaGreen Supermix kit (Bio-Rad, Munich). qRTPCR conditions consisted of an initial incubation step at $95^{\circ} \mathrm{C}$ for 30 $\mathrm{s}$, followed by 40 cycles of $10 \mathrm{~s}$ of denaturation at $95^{\circ} \mathrm{C}$ and $15 \mathrm{~s}$ of annealing at $60^{\circ} \mathrm{C}$. Primers based on the internal transcribed spacer sequence between $16 \mathrm{~S}$ and $23 \mathrm{~S}$ rDNA were used as an internal standard for normalization. All reactions were performed in triplicate and were repeated three times.

\section{Plasmid curing.}

Plasmids present in $C$. michiganensis subsp. michiganensis CASJ001 and CASJ002 were cured by a modified procedure described by Meletzus et al. (1993). C. michiganensis subsp. michiganensis was grown in $\mathrm{C}$ medium (per liter: peptone at 10 $\mathrm{g}$, yeast extract at $5 \mathrm{~g}$, glucose at $5 \mathrm{~g}, \mathrm{NaCl}$ at $5 \mathrm{~g}, \mathrm{pH} 7.2$ to 7.4 ) at $28^{\circ} \mathrm{C}$ until late log phase (optical density at $600 \mathrm{~nm}=1$ ). One milliliter of late $\log$ phase culture was transferred into $50 \mathrm{ml}$ of $\mathrm{C}$ medium in a $500-\mathrm{ml}$ flask and was grown at $34^{\circ} \mathrm{C}$ to approximately $10^{8}$ cells per milliliter. Dilutions were spread on $\mathrm{C}$ medium agar plates and were incubated at $24^{\circ} \mathrm{C}$. Colonies were then tested for endocellulase activity, in order to identify those that lacked pCM1. Briefly, colonies from these plates were picked and replica-plated onto M9 CMC agar plates (consisting of M9 medium supplemented with $0.1 \%$ [wt/vol] yeast extract and $0.5 \%$ [wt/vol] carboxymethylcellulose [Joseph and David 2001] and C medium). Plates were incubated for 5 days at $25^{\circ} \mathrm{C}$, were then stained with $0.1 \%$ (wt/vol) Congo red for $20 \mathrm{~min}$, and were bleached with $1 \mathrm{M} \mathrm{NaCl}$. Endocellulase activity was detected as a clear, yellowish halo around the colonies. Plasmid curing was confirmed by PCR and sequencing with primers targeting the celA gene, in plasmid pCM1, and pat-1 gene, in plasmid pCM2.

\section{CelA expression and cloning.}

The celA gene was amplified with the EcoR_celAF1/R1 primer pair from $C$. michiganensis subsp. michiganensis CASJ001 and CASJ002. The amplified PCR product was digested with EcoRI (Promega). The pHN216 vector (Laine et al. 1996) was digested with EcoRI overnight at $37^{\circ} \mathrm{C}$, was treated with Antarctic phosphatase, and was ligated with EcoRI-digested CelA using T4 DNA ligase. The pHN216celA was transformed into $E$. coli $\mathrm{DH} 5 \alpha$ and was selected on LB medium containing neomycin $(50 \mu \mathrm{g} / \mathrm{ml})$. The presence of the CelA gene in the recombinant plasmid clone was confirmed by PCR and sequencing. Plasmid DNA isolation and C. michiganensis subsp. michiganensis transformation was performed as described above. After electroporation, cells were incubated on SB agar plates containing neomycin $(50 \mu \mathrm{g} / \mathrm{ml})$ for 5 to 7 days.

\section{ACKNOWLEDGMENTS}

We thank K.-H. Gartemann for his advice on genetic manipulation of C. michiganensis subsp. michiganensis and proving the pHN216 and pOKU9 $\mathrm{cmB} \alpha$ plasmids. G. Coaker, S. Thapa, and R. L. Gilbertson were supported by grants from the California Tomato Research Institute awarded to G. Coaker and R. L. Gilbertson. G. Coaker and S. Thapa were supported by a grant from USDA-NIFA (2015-67013-23082, awarded to G. Coaker). The generation of the CCRC series of plant cell-wall glycan-directed monoclonal antibodies used in this work was supported by the National Science Foundation Plant Genome Program (DBI-0421683 and IOS-0923992, awarded to M. G. Hahn).

\section{LITERATURE CITED}

Abbott, D. W., and Boraston, A. B. 2008. Structural biology of pectin degradation by Enterobacteriaceae. Microbiol. Mol. Biol. Rev. 72:301-316. 
Alarcón, C., Castro, J., Muñoz, F., Arce-Johnson, P., and Delgado, J. 1998. Protein(s) from the gram-positive bacterium Clavibacter michiganensis subsp. michiganensis induces a hypersensitive response in plants. Phytopathology 88:306-310.

Bankevich, A., Nurk, S., Antipov, D., Gurevich, A. A., Dvorkin, M., Kulikov, A. S., Lesin, V. M., Nikolenko, S. I., Pham, S., Prjibelski, A. D., Pyshkin, A. V., Sirotkin, A. V., Vyahhi, N., Tesler, G., Alekseyev, M. A., and Pevzner, P. A. 2012. SPAdes: A new genome assembly algorithm and its applications to single-cell sequencing. J. Comput. Biol. 19:455-477.

Barnes, S. E., and Shaw, M. W. 2003. Infection of commercial hybrid primula seed by Botrytis cinerea and latent disease spread through the plants. Phytopathology 93:573-578.

Bellanger, X., Payot, S., Leblond-Bourget, N., and Guédon, G. 2014. Conjugative and mobilizable genomic islands in bacteria: Evolution and diversity. FEMS Microbiol. Rev. 38:720-760.

Bendtsen, J. D., Nielsen, H., Widdick, D., Palmer, T., and Brunak, S. 2005. Prediction of twin-arginine signal peptides. BMC Bioinformatics 6:167.

Bentley, S. D., Corton, C., Brown, S. E., Barron, A., Clark, L., Doggett, J., Harris, B., Ormond, D., Quail, M. A., May, G., Francis, D., Knudson, D., Parkhill, J., and Ishimaru, C. A. 2008. Genome of the actinomycete plant pathogen Clavibacter michiganensis subsp. sepedonicus suggests recent niche adaptation. J. Bacteriol. 190:2150-2160.

Brown, S. E., Knudson, D. L., and Ishimaru, C. A. 2002. Linear plasmid in the genome of Clavibacter michiganensis subsp. sepedonicus. J. Bacteriol. 184:2841-2844

Cantarel, B. L., Coutinho, P. M., Rancurel, C., Bernard, T., Lombard, V., and Henrissat, B. 2009. The Carbohydrate-Active EnZymes database (CAZy): An expert resource for Glycogenomics. Nucleic Acids Res. 37: D233-D238.

Chalupowicz, L., Barash, I., Reuven, M., Dror, O., Sharabani, G., Gartemann, K. H., Eichenlaub, R., Sessa, G., and Manulis-Sasson, S. 2017. Differential contribution of Clavibacter michiganensis ssp. michiganensis virulence factors to systemic and local infection in tomato. Mol. Plant Pathol. 18: 336-346.

Chalupowicz, L., Cohen-Kandli, M., Dror, O., Eichenlaub, R., Gartemann, K. H., Sessa, G., Barash, I., and Manulis-Sasson, S. 2010. Sequential expression of bacterial virulence and plant defense genes during infection of tomato with Clavibacter michiganensis subsp. michiganensis. Phytopathology 100:252-261.

Chalupowicz, L., Zellermann, E. M., Fluegel, M., Dror, O., Eichenlaub, R., Gartemann, K. H., Savidor, A., Sessa, G., Iraki, N., Barash, I., and ManulisSasson, S. 2012. Colonization and movement of GFP-labeled Clavibacter michiganensis subsp. michiganensis during tomato infection. Phytopathology 102:23-31.

Chang, J. H., Desveaux, D., and Creason, A. L. 2014. The ABCs and 123s of bacterial secretion systems in plant pathogenesis. Annu. Rev. Phytopathol. 52:317-345

Chin, C. S., Alexander, D. H., Marks, P., Klammer, A. A., Drake, J., Heiner, C., Clum, A., Copeland, A., Huddleston, J., Eichler, E. E., Turner, S. W., and Korlach, J. 2013. Nonhybrid, finished microbial genome assemblies from long-read SMRT sequencing data. Nat. Methods 10:563-569.

Cornelis, G. R. 2010. The type III secretion injectisome, a complex nanomachine for intracellular 'toxin' delivery. Biol. Chem. 391:745-751.

Cunnac, S., Chakravarthy, S., Kvitko, B. H., Russell, A. B., Martin, G. B., and Collmer, A. 2011. Genetic disassembly and combinatorial reassembly identify a minimal functional repertoire of type III effectors in Pseudomonas syringae. Proc. Natl. Acad. Sci. U.S.A. 108:2975-2980

Darrasse, A., Darsonval, A., Boureau, T., Brisset, M. N., Durand, K., and Jacques, M. A. 2010. Transmission of plant-pathogenic bacteria by nonhost seeds without induction of an associated defense reaction at emergence. Appl. Environ. Microbiol. 76:6787-6796.

de León, L., Siverio, F., López, M. M., and Rodríguez, A. 2011. Clavibacter michiganesis subsp. michiganensis, a seedborne tomato pathogen: Healthy seeds are still the goal. Plant Dis. 95:1328-1338.

Dhillon, B. K., Laird, M. R., Shay, J. A., Winsor, G. L., Lo, R., Nizam, F., Pereira, S. K., Waglechner, N., McArthur, A. G., Langille, M. G., and Brinkman, F. S. 2015. IslandViewer 3: More flexible, interactive genomic island discovery, visualization and analysis. Nucleic Acids Res. 43 (W1):W104-W108.

Ding, S., Huang, C. L., Sheng, H. M., Song, C. L., Li, Y. B., and An, L. Z. 2011. Effect of inoculation with the endophyte Clavibacter sp. strain Enf12 on chilling tolerance in Chorispora bungeana. Physiol. Plant. 141:141-151.

Dou, D., and Zhou, J.-M. 2012. Phytopathogen effectors subverting host immunity: Different foes, similar battleground. Cell Host Microbe 12: 484-495.

Dreier, J., Meletzus, D., and Eichenlaub, R. 1997. Characterization of the plasmid encoded virulence region pat-1 of phytopathogenic Clavibacter michiganensis subsp. michiganensis. Mol. Plant-Microbe Interact 10: 195-206.
Eddy, S. R. 2009. A new generation of homology search tools based on probabilistic inference. Genome Inform. 23:205-211.

Eichenlaub, R., and Gartemann, K. H. 2011. The Clavibacter michiganensis subspecies: Molecular investigation of gram-positive bacterial plant pathogens. Annu. Rev. Phytopathol. 49:445-464.

Eichenlaub, R., Gartemann, K.-H., and Burger, A. 2006. Clavibacter michiganensis, a group of gram-positive phytopathogenic bacteria. Pages 385-421 in: Plant-Associated Bacteria. S. S. Gnanamanickam, ed. Springer, Dordrecht, The Netherlands.

Francis, I., Holsters, M., and Vereecke, D. 2010. The gram-positive side of plant-microbe interactions. Environ. Microbiol. 12:1-12.

Gartemann, K. H., Abt, B., Bekel, T., Burger, A., Engemann, J., Flügel, M., Gaigalat, L., Goesmann, A., Gräfen, I., Kalinowski, J., Kaup, O., Kirchner, O., Krause, L., Linke, B., McHardy, A., Meyer, F., Pohle, S., Rückert, C. Schneiker, S., Zellermann, E. M., Pühler, A., Eichenlaub, R., Kaiser, O., and Bartels, D. 2008. The genome sequence of the tomato-pathogenic actinomycete Clavibacter michiganensis subsp. michiganensis NCPPB382 reveals a large island involved in pathogenicity. J. Bacteriol. 190:2138-2149.

Gartemann, K.-H., and Eichenlaub, R. 2001. Isolation and characterization of IS1409, an insertion element of 4-chlorobenzoate-degrading Arthrobacter sp. strain TM1, and development of a system for transposon mutagenesis. J. Bacteriol. 183:3729-3736.

Gartemann, K. H., Kirchner, O., Engemann, J., Gräfen, I., Eichenlaub, R., and Burger, A. 2003. Clavibacter michiganensis subsp. michiganensis: First steps in the understanding of virulence of a gram-positive phytopathogenic bacterium. J. Biotechnol. 106:179-191.

Geisseler D, Horwath WR. 2014. Production of processing tomatoes in California. Fertilizer Resaerch and Education Program, California Department of Food and Agriculture, Sacramento, CA, U.S.A.

Gitaitis, R. 1990. Induction of a hypersensitivelike reaction in four-o'clock by Clavibacter michiganensis subsp. michiganensis. Plant Dis. 74:58-60.

Gitaitis, R., Beaver, R., and Voloudakis, A. 1991. Detection of Clavibacter michiganensis subsp. michiganensis in symptomless tomato transplants. Plant Dis. 75:834-838.

González, A. J., and Trapiello, E. 2014. Clavibacter michiganensis subsp. phaseoli subsp. nov., pathogenic in bean. Int. J. Syst. Evol. Microbiol. 64: 1752-1755.

Hardoim, P. R., van Overbeek, L. S., Berg, G., Pirttilä, A. M., Compant, S., Campisano, A., Döring, M., and Sessitsch, A. 2015. The hidden world within plants: Ecological and evolutionary considerations for defining functioning of microbial endophytes. Microbiol. Mol. Biol. Rev. 79:293-320.

Hsiao, W. W., Ung, K., Aeschliman, D., Bryan, J., Finlay, B. B., and Brinkman, F. S. 2005. Evidence of a large novel gene pool associated with prokaryotic genomic islands. PLoS Genet. 1:e62.

Jacques, M. A., Durand, K., Orgeur, G., Balidas, S., Fricot, C., Bonneau, S., Quillévéré, A., Audusseau, C., Olivier, V., Grimault, V., and Mathis, R. 2012. Phylogenetic analysis and polyphasic characterization of Clavibacter michiganensis strains isolated from tomato seeds reveal that nonpathogenic strains are distinct from C. michiganensis subsp. michiganensis. Appl. Environ. Microbiol. 78:8388-8402.

Joseph, S., and David, W. R. 2001. Molecular Cloning: A Laboratory Manual. Cold Spring Harbor Laboratory Press, New York.

Juncker, A. S., Willenbrock, H., Von Heijne, G., Brunak, S., Nielsen, H., and Krogh, A. 2003. Prediction of lipoprotein signal peptides in gram-negative bacteria. Protein Sci. 12:1652-1662.

Kado, C. I., and Heskett, M. G. 1970. Selective media for isolation of Agrobacterium, Corynebacterium, Erwinia, Pseudomonas, and Xanthomonas. Phytopathology 60:969-976.

Kaup, O., Gräfen, I., Zellermann, E. M., Eichenlaub, R., and Gartemann, K. H. 2005. Identification of a tomatinase in the tomato-pathogenic actinomycete Clavibacter michiganensis subsp. michiganensis NCPPB382. Mol. Plant-Microbe Interact 18:1090-1098.

Kirchner, O., Gartemann, K. H., Zellermann, E. M., Eichenlaub, R., and Burger, A. 2001. A highly efficient transposon mutagenesis system for the tomato pathogen Clavibacter michiganensis subsp. michiganensis. Mol. Plant-Microbe Interact 14:1312-1318.

Krzywinski, M., Schein, J., Birol, I., Connors, J., Gascoyne, R., Horsman, D., Jones, S. J., and Marra, M. A. 2009. Circos: An information aesthetic for comparative genomics. Genome Res. 19:1639-1645.

Kück, P., and Meusemann, K. 2010. FASconCAT: Convenient handling of data matrices. Mol. Phylogenet. Evol. 56:1115-1118.

Laine, M. J., Nakhei, H., Dreier, J., Lehtilä, K., Meletzus, D., Eichenlaub, R., and Metzler, M. C. 1996. Stable transformation of the gram-positive phytopathogenic bacterium Clavibacter michiganensis subsp. sepedonicus with several cloning vectors. Appl. Environ. Microbiol. 62:1500-1506.

Langille, M. G., Hsiao, W. W., and Brinkman, F. S. 2008. Evaluation of genomic island predictors using a comparative genomics approach BMC Bioinformatics 9:329. 
Letunic, I., and Bork, P. 2007. Interactive tree of life (iTOL): An online tool for phylogenetic tree display and annotation. Bioinformatics 23:127-128.

Li, L., Stoeckert, C. J., Jr., and Roos, D. S. 2003. OrthoMCL: Identification of ortholog groups for eukaryotic genomes. Genome Res. 13:2178-2189.

Li, W., and Godzik, A. 2006. Cd-hit: A fast program for clustering and comparing large sets of protein or nucleotide sequences. Bioinformatics 22:1658-1659.

Löytynoja, A., and Goldman, N. 2005. An algorithm for progressive multiple alignment of sequences with insertions. Proc. Natl. Acad. Sci. U.S.A. 102:10557-10562.

Lu, Y., Hatsugai, N., Katagiri, F., Ishimaru, C. A., and Glazebrook, J. 2015a. Putative serine protease effectors of Clavibacter michiganensis induce a hypersensitive response in the apoplast of Nicotiana species. Mol. PlantMicrobe Interact 28:1216-1226.

Lu, Y., Samac, D. A., Glazebrook, J., and Ishimaru, C. A. 2015b. Complete genome sequence of Clavibacter michiganensis subsp. insidiosus R1-1 using PacBio single-molecule real-time technology. Genome Announc. 3:e00396-15.

Mansfield, J., Genin, S., Magori, S., Citovsky, V., Sriariyanum, M., Ronald, P., Dow, M., Verdier, V., Beer, S. V., Machado, M. A., Toth, I., Salmond, G., and Foster, G. D. 2012. Top 10 plant pathogenic bacteria in molecular plant pathology. Mol. Plant Pathol. 13:614-629.

Meletzus, D., Bermphol, A., Dreier, J., and Eichenlaub, R. 1993. Evidence for plasmid-encoded virulence factors in the phytopathogenic bacterium Clavibacter michiganensis subsp. michiganensis NCPPB382. J. Bacteriol. 175:2131-2136.

Milijašević-Marčić, S., Gartemann, K.-H., Frohwitter, J., Eichenlaub, R., Todorović, B., Rekanović, E., and Potočnik, I. 2012. Characterization of Clavibacter michiganensis subsp. michiganensis strains from recent outbreaks of bacterial wilt and canker in Serbia. Eur. J. Plant Pathol. 134: 697-711.

Mogen, B. D., and Oleson, A. E. 1987. Homology of pCS1 plasmid sequences with chromosomal DNA in Clavibacter michiganense subsp. sepedonicum: Evidence for the presence of a repeated sequence and plasmid integration. Appl. Environ. Microbiol. 53: 2476-2481

Nissinen, R., Xia, Y., Mattinen, L., Ishimaru, C. A., Knudson, D. L., Knudson, S. E., Metzler, M., and Pirhonen, M. 2009. The putative secreted serine protease Chp-7 is required for full virulence and induction of a nonhost hypersensitive response by Clavibacter michiganensis subsp. sepedonicus. Mol. Plant-Microbe Interact 22:809-819.

Official Journal of the European Communities. 2000. Council Directive 2000/29/EC of May 8, 2000 on protective measures against the introduction into the community of organisms harmful to plants or plant products and against their spread within the community. Pages 1-159 in: Official Publications of the European Communities. http://eur-lex.europa.eu/legal-content/ EN/TXT/?uri=celex:32000L0029. Publicaton Office of the European Union, Luxembourg, Belgium.

Palmer, B. R., and Marinus, M. G. 1994. The dam and dcm strains of Escherichia coli-A review. Gene 143:1-12.

Pattathil, S., Avci, U., Baldwin, D., Swennes, A. G., McGill, J. A., Popper, Z., Bootten, T., Albert, A., Davis, R. H., Chennareddy, C., Dong, R., O'Shea, B., Rossi, R., Leoff, C., Freshour, G., Narra, R., O’Neil, M., York, W. S. and Hahn, M. G. 2010. A comprehensive toolkit of plant cell wall glycandirected monoclonal antibodies. Plant Physiol. 153:514-525.

Pattathil, S., Avci, U., Miller, J. S., and Hahn, M. G. 2012. Immunological approaches to plant cell wall and biomass characterization: Glycome profiling. Methods Mol. Biol. 908:61-72.

Petersen, T. N., Brunak, S., von Heijne, G., and Nielsen, H. 2011. SignalP 4.0: Discriminating signal peptides from transmembrane regions. Nat. Methods 8:785-786.

Ploch, S., and Thines, M. 2011. Obligate biotrophic pathogens of the genus Albugo are widespread as asymptomatic endophytes in natural populations of Brassicaceae. Mol. Ecol. 20:3692-3699.

Quesada-Ocampo, L. M., Landers, N. A., Lebeis, A. C., Fulbright, D. W., and Hausbeck, M. K. 2012. Genetic structure of Clavibacter michiganensis subsp. michiganensis populations in Michigan commercial tomato fields. Plant Dis. 96:788-796.
Quevillon, E., Silventoinen, V., Pillai, S., Harte, N., Mulder, N., Apweiler, R., and Lopez, R. 2005. InterProScan: Protein domains identifier. Nucleic Acids Res. 33:W116-W120.

Savidor, A., Chalupowicz, L., Teper, D., Gartemann, K. H., Eichenlaub, R., Manulis-Sasson, S., Barash, I., and Sessa, G. 2014. Clavibacter michiganensis subsp. michiganensis Vatr1 and Vatr2 transcriptional regulators are required for virulence in tomato. Mol. Plant-Microbe Interact 27:1035-1047.

Seemann, T. 2014. Prokka: Rapid prokaryotic genome annotation. Bioinformatics 30:2068-2069.

Sen, Y., van der Wolf, J., Visser, R. G. F., and van Heusden, S. 2015. Bacterial canker of tomato: Current knowledge of detection, management, resistance, and interactions. Plant Dis. 99:4-13.

Sonnhammer, E. L., von Heijne, G., and Krogh, A. 1998. A hidden Markov model for predicting transmembrane helices in protein sequences. Proc. Int. Conf. Intell. Syst. Mol. Biol. 6:175-182.

Soueidan, H., Maurier, F., Groppi, A., Sirand-Pugnet, P., Tardy, F., Citti, C., Dupuy, V., and Nikolski, M. 2013. Finishing bacterial genome assemblies with Mix. BMC Bioinformatics 14 (Suppl 15):S16.

Sowley, E. N. K., Dewey, F. M., and Shaw, M. W. 2010. Persistent, symptomless, systemic, and seed-borne infection of lettuce by Botrytis cinerea. Eur. J. Plant Pathol. 126:61-71.

Stamatakis, A. 2006. RAxML-VI-HPC: Maximum likelihood-based phylogenetic analyses with thousands of taxa and mixed models. Bioinformatics 22:2688-2690.

Stork, I., Gartemann, K. H., Burger, A., and Eichenlaub, R. 2008. A family of serine proteases of Clavibacter michiganensis subsp. michiganensis: chpC plays a role in colonization of the host plant tomato. Mol. Plant Pathol. 9:599-608.

Tamura, K., Stecher, G., Peterson, D., Filipski, A., and Kumar, S. 2013. MEGA6: Molecular evolutionary genetics analysis version 6.0. Mol. Biol. Evol. 30:2725-2729.

Tancos, M. A., Lange, H. W., and Smart, C. D. 2015. Characterizing the genetic diversity of the Clavibacter michiganensis subsp. michiganensis po in New York. Phytopathology 105:169-179.

Tatusova, T., DiCuccio, M., Badretdin, A., Chetvernin, V., Nawrocki, E. P., Zaslavsky, L., Lomsadze, A., Pruitt, K. D., Borodovsky, M., and Ostell, J. 2016. NCBI prokaryotic genome annotation pipeline. Nucleic Acids Res. 44:6614-6624.

Tauch, A., Zheng, Z., Pühler, A., and Kalinowski, J. 1998. Corynebacterium striatum chloramphenicol resistance transposon Tn5564: Genetic organization and transposition in Corynebacterium glutamicum. Plasmid 40: 126-139.

Thapa, S. P., Miyao, E. M., Michael Davis, R., and Coaker, G. 2015. Identification of QTLs controlling resistance to Pseudomonas syringae pv. tomato race 1 strains from the wild tomato, Solanum habrochaites LA1777. Theor. Appl. Genet. 128:681-692.

Toruño, T. Y., Stergiopoulos, I., and Coaker, G. 2016. Plant-pathogen effectors: Cellular probes interfering with plant defenses in spatial and temporal manners. Annu. Rev. Phytopathol. 54:419-441.

Waack, S., Keller, O., Asper, R., Brodag, T., Damm, C., Fricke, W. F., Surovcik, K., Meinicke, P., and Merkl, R. 2006. Score-based prediction of genomic islands in prokaryotic genomes using hidden Markov models. BMC Bioinformatics 7:142.

Yasuhara-Bell, J., and Alvarez, A. M. 2015. Seed-associated subspecies of the genus Clavibacter are clearly distinguishable from Clavibacter michiganensis subsp. michiganensis. Int. J. Syst. Evol. Microbiol. 65:811-826.

Yin, Y., Mao, X., Yang, J., Chen, X., Mao, F., and Xu, Y. 2012. dbCAN: A web resource for automated carbohydrate-active enzyme annotation. Nucleic Acids Res. 40:W445-W451.

Zaluga, J., Van Vaerenbergh, J., Stragier, P., Maes, M., and De Vos, P. 2013. Genetic diversity of non-pathogenic Clavibacter strains isolated from tomato seeds. Syst. Appl. Microbiol. 36:426-435.

\section{AUTHOR-RECOMMENDED INTERNET RESOURCES}

CarboSource Services: http://www.carbosource.net

FigTree program (version 1.4. 0): http://tree.bio.ed.ac.uk/software/figtree/ WallMabDB website: http://www.wallmabdb.net 